\title{
Improving Broiler Performance and Digestibility Through Feed Enzymes and Production Rate Aids Utilized in Pelleting.
}

Kristina Marie Bowen

West Virginia University, kmb00014@mix.wvu.edu

Follow this and additional works at: https://researchrepository.wvu.edu/etd

\section{Recommended Citation}

Bowen, Kristina Marie, "Improving Broiler Performance and Digestibility Through Feed Enzymes and Production Rate Aids Utilized in Pelleting." (2021). Graduate Theses, Dissertations, and Problem Reports. 10346.

https://researchrepository.wvu.edu/etd/10346

This Thesis is protected by copyright and/or related rights. It has been brought to you by the The Research Repository @ WVU with permission from the rights-holder(s). You are free to use this Thesis in any way that is permitted by the copyright and related rights legislation that applies to your use. For other uses you must obtain permission from the rights-holder(s) directly, unless additional rights are indicated by a Creative Commons license in the record and/ or on the work itself. This Thesis has been accepted for inclusion in WVU Graduate Theses, Dissertations, and Problem Reports collection by an authorized administrator of The Research Repository @ WVU. For more information, please contact researchrepository@mail.wvu.edu. 


\title{
Improving Broiler Performance and Digestibility Through Feed Enzymes and Production Rate Aids Utilized in Pelleting.
}

\author{
Kristina Marie Bowen \\ Thesis submitted To the Davis College of Agriculture, Natural Resources, and Design \\ At West Virginia University \\ In partial fulfillment of the requirements for the degree of \\ Master of Science in Nutrition and Food Science \\ Joseph Moritz, Ph.D., Chair \\ Janet Tou, Ph.D. \\ K. Marie Krause, Ph.D. \\ Department of Division of Animal and Nutritional Sciences
}

Morgantown, West Virginia

2021

Keywords: Phytase, Inorganic Phosphorus, Feed Additive, Broiler, Mill Energy Consumption Copyright 2021 Kristina M. Bowen 


\section{ABSTRACT \\ Improving Broiler Performance and Digestibility Through Feed Enzymes and Production Rate Aids Utilized in Pelleting.}

\section{Kristina Marie Bowen}

Enzymes are commonly added to poultry diets to improve performance parameters that may in turn decrease costs to the producer. Pellet mill production rate aids are also utilized to reduce feed manufacture costs and may have additional benefits when fed to poultry that are associated with the increase in production rate. Past research has shown that Azomite (AZM) can increase pellet mill production rate in diets that include inorganic phosphate sources (IPS) of dicalcium phosphate (DCP) or tricalcium phosphate (TCP). In the first experiment the authors hypothesized that if production rate were held constant then pellet mill energy consumption would decrease for diets that contained AZM due in part to a lubricating and/or pellet die scouring effect. This could decrease dietary amino acid exposure to frictional heat and pressure within the pellet die, maintaining amino acid conformation, and amino acid digestibility. The objective was to determine the effect of AZM $(0.25 \%)$ in diets with DCP and TCP on pellet mill energy consumption, subsequent live bird performance, and apparent ileal amino acid digestibility (AIAAD) when fed to broiler chicks for 21 days. Feed was manufactured in a 2 (IPS) x 2 (AZM inclusion) factorial across 4 days in a Latin square design. Post manufacture, three hundred twenty-day-old Hubbard $\times$ Ross 708 males $(0.038 \mathrm{~kg} \pm 0.0014$ SD) were allocated by weight to 8 replicates per treatment, 10 chicks per raised wire cage, in a randomized complete block design. Dietary treatments were arranged in a 2 x 2 factorial: DCP with or without AZM and TCP with or without AZM. On d21 ileal contents were collected for amino acid and titanium dioxide analysis. Statistical analysis (Glimmix, SAS 9.4) was performed on the factorial arrangement of treatments and multiple comparisons were made of all treatments with post-hoc test by Tukey's. Pellet mill motor load decreased by $5 \%$ in diets containing TCP compared to DCP $(P<0.001)$, and $1 \%$ when AZM was included $(P<0.001)$. An IPS $\times$ AZM inclusion interaction occurred for pellet durability $(P<0.001)$ and hot pellet temperature $(P<0.05)$. Pellet durability was increased in diets containing DCP when AZM was included, while TCP were unaffected. Hot pellet temperature increased for TCP diets with AZM, whereas DCP diets did not change. Apparent ileal digestibility of lysine, cysteine, and isoleucine were affected by the interaction of IPS and AZM inclusion $(P<0.05)$, demonstrating that processing with AZM increased digestibility in DCP diets but not TCP diets. Despite increased amino acid digestibility, AZM in DCP diets increased feed conversion ratio (FCR) by $0.02(1.284$ vs $1.303, P<0.05)$. However, AZM did not affect FCR in TCP diets (1.294 vs 1.285, P>0.05). Decreased pellet mill motor load that resulted from AZM inclusion suggests that feed was subjected to less frictional heat and/or pressure within the pellet die. This reduction in frictional heat and pressure likely preserved amino acid conformation, but the improvement was not translated to growth efficiency.

Mixer added phytases must retain efficacy post conditioning and pelleting. Heat from saturated steam and friction upon pellet die extrusion may deactivate phytases. In addition, increasing phytase concentrations in diets may increase nutrient release from phytate. In this second experiment the objective was to assess two commercially available phytases that were 
concentrated at $500,1,000$, or $2,000 \mathrm{FTU} / \mathrm{kg}$ in mixed mash post steam conditioning at $82^{\circ} \mathrm{C}$ for $30 \mathrm{sec}$ and extrusion through a 4.8 x $38 \mathrm{~mm}$ pellet die on 0 to 44d Ross 708 male broiler performance, mineral digestibility, and tibia ash responses. The phytase sources were both derived from E. coli and expressed in Trichoderma Reesei, (QB) and expressed in Pichia pastoris, (OP). A 3 (Phytase level) $\times 2$ (Phytase source) factorial arrangement of treatments within a randomized complete block design was utilized. A positive control and negative control diet based on available phosphorus $(\mathbf{P})$ and total calcium $(\mathbf{C a})$ were also manufactured and analyzed within a multiple comparison. Crumbled and pelleted diets were fed to 8 replicate pens of 30 chicks in three phases. Live performance, d20 and d44 tibia ash, d44 hot boneless, skinless breast weight and mineral digestibility were measured. Day 44 live weight gain (LWG) and both d20 and d44 tibia measures increased for all phytase concentrations relative to the negative control $(P<0.05)$. Phytase sources did not differ in their effect on live performance or breast yield with the exception of live weight at 20 days where birds provided with OP were heavier $(P<0.05)$. Calcium digestibility was increased for birds fed OP relative to QB $(P<0.05)$. Phosphorus digestibility increased when either source was fed and was higher with OP compared to QB at $500 \mathrm{FTU} / \mathrm{kg}(P<0.05)$. Day 20 tibia ash percentage increased for 1,000 and 2,000 FTU/kg concentrations for both phytase sources while mg tibia ash increased with all levels of both sources compared to the control $(P<0.05)$. Mg tibia ash was higher with OP compared to $\mathrm{QB}$ at the $500 \mathrm{FTU}$ level $(P<0.05)$. Both phytase sources increased d44 percent and $\mathrm{mg}$ tibia ash relative to the negative control with OP exceeding QB at 1,000 and 2,000 FTU for tibia ash percent and at 2,000 FTU for $\mathrm{mg}$ tibia ash $(P<0.05)$. The assessed phytase sources showed similar benefit to live performance and breast yield but varied in response to tibia ash and mineral digestibility at different concentrations. 


\section{ACKNOWLEDGMENTS}

I would like to express my deepest appreciation to my advisor, Dr. Joe Moritz, for giving me this amazing opportunity. He has provided me with invaluable knowledge and experience that I would not have been able to obtain elsewhere. I am forever grateful that he has been patient and understanding throughout my journey at WVU. I would also like to extend my deepest gratitude to the members of my committee: Drs. Janet Tou and Marie Krause for their help and guidance. I would not have been able to succeed without their time. I would also like to thank my lab group: Elizabeth Lynch, Tim Boltz, and Victoria Ayres. Their endless hours of help allowed me to complete my research. I would also like to thank the undergraduates who helped me with my research. I cannot begin to express my thanks to my partner and best friend, Joe Leszcz, who has offered his support at every step and through every struggle, helping in any way that he could. I would not be where I am today without him. I am also grateful to my family, who have offered their support throughout my educational journey. Lastly, a special thanks to Dr. Zachary Williams, for his support and the opportunities that he has given me. 


\section{TABLE OF CONTENTS}

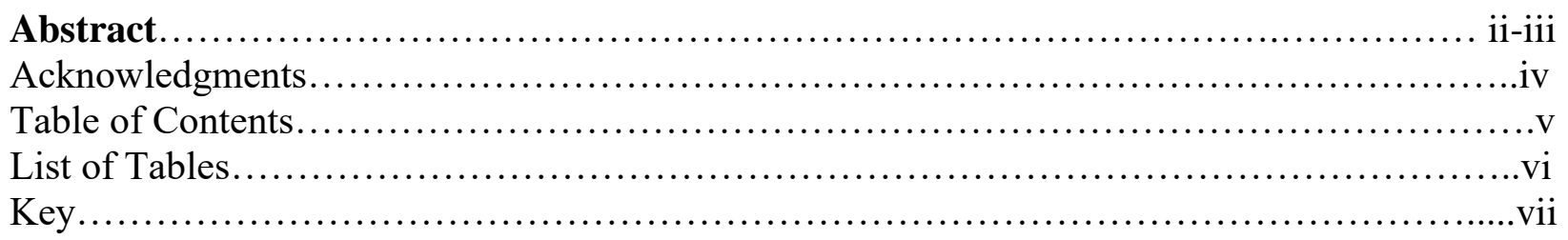

CHAPTER 1: LITERATURE REVIEW .............................................

Phosphorus and Phytate........................................................ 1-3

Feed Additives........................................................................

Amino Acids/Proteins.......................................................... $9-11$

Feed Form ......................................................................

References........................................................................... 18

CHAPTER 2: The effect of a dacitic (rhyolitic) tuff breccia (Azomite $\left.{ }^{\circledR}\right)$ in corn, soybean, and DDGS based diets that vary in inorganic phosphate source on pellet mill energy use, 0 to 21-day broiler performance, and apparent ileal amino acid digestibility....

Summary 20-21

Description of the Problem....................................................... 21-24

Materials and Methods.............................................................24-29

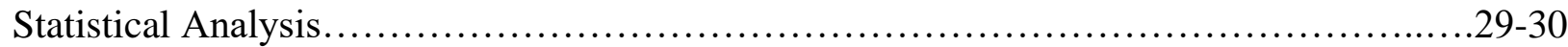

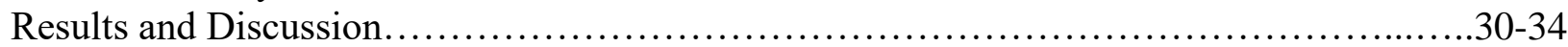

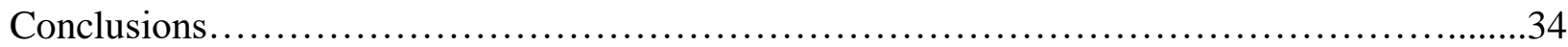

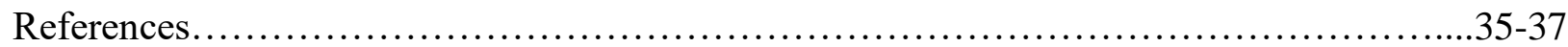

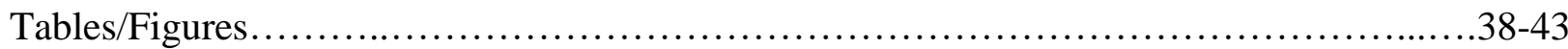

CHAPTER 3: Performance, Carcass Quality, Tibia ash, and Mineral Digestibility Responses of Ross 708 Broilers to Increasing Dose of Two Commercially Available Mixer-added Phytases.

Summary

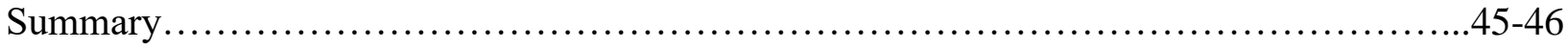

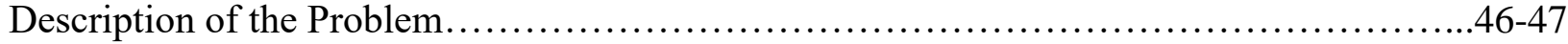

Materials and Methods.............................................................. $47-52$

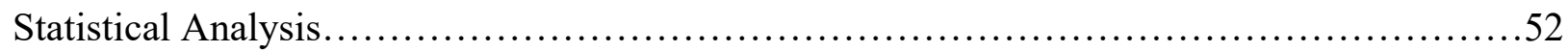

Results and Discussion........................................................... $52-55$

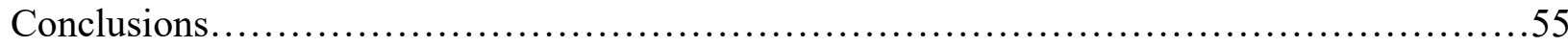

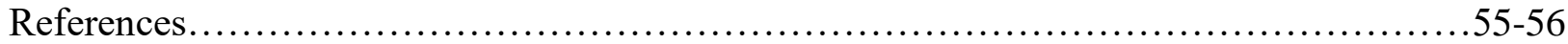

Tables/Figure.......................................................... 57-61

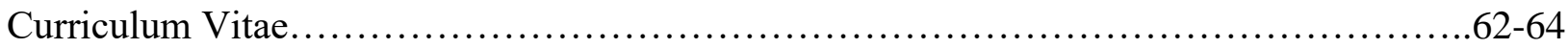




\section{LIST OF TABLES}

\section{Chapter 2}

Table 1. Broiler finisher formulations for diets containing dicalcium phosphate (DCP) or tricalcium phosphate (TCP) $(\%$ diet $)$

Table 2. Feed particle size for feed manufactured at the WVU pilot mill in July, 2020. Feed was manufactured using a 40 horsepower California Pellet Mill and were extruded through a $4.8 \times 38$

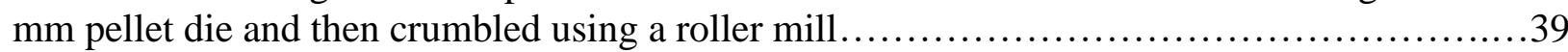

Table 3. Analyzed Nutrients for Phosphate Sources, Azomite product, and DDGS..............39 Table 4. The effects of phosphate source and Azomite inclusion on feed manufacture variables

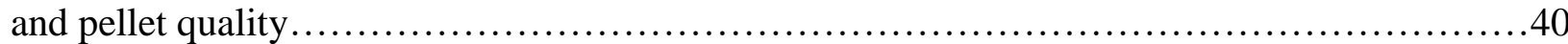

Table 5. Apparent Ileal Digestibility (AIAAD) of 21-day old broilers.......................41

Table 6. The effects of phosphate source and Azomite inclusion on live bird performance of Hubbard $\times$ Ross 708 broiler chicks ..................................................42

Figure 1. 50,000-scanning electron microscope of Azomite feed grit with an FEI..............43

\section{Chapter 3}

Table 1. Broiler diet formulations and analyzed values of pelleted diets...................57

Table 2. Descriptive Feed Manufacture Data from WVU Feed Mill. Feed was manufactured using a 40 horsepower California Pellet Mill and were extruded through a 4.8 x $38 \mathrm{~mm}$ pellet die into one positive control batch and seven negative control batches for each feeding phase.....58 Table 3: D 0-20 Performance of Ross 708 broilers fed control feed and increasing doses of Optiphos Plus and Quantum Blue

Table 4: D 0-44 Performance of Ross 708 broilers fed control feed and increasing doses of Optiphos Plus and Quantum Blue. .60

Table 5: Mineral Digestibility, Tibia Ash Analysis, and Breast Measurements of Ross 708 broilers fed control feed and increasing doses of Optiphos Plus and Quantum Blue. 


\section{CHAPTER 1:}

1. Phosphorus $-\mathrm{P}$

2. Gastrointestinal-GI

3. Phytase Units - FTU

4. Feed Conversion Ratio - FCR

5. Body Weight Gain - BWG

6. Feed Intake - FI

7. Live Weight Gain - LWG

8. Escherichia Coli-E. coli

9. Aspergillus niger - A. niger

10. polymerase chain reaction $-\mathrm{PCR}$

11. metric ton per hour $-\mathrm{MT} / \mathrm{hr}$

12. pellet durability index $-\mathrm{PDI}$

13. sudden death syndrome - SDS

\section{CHAPTER 2:}

1. Azomite - AZM

2. Dried Distillers' Grains with Solubles - DDGS

3. Phosphorus $-\mathrm{P}$

4. Calcium $-\mathrm{Ca}$

5. Tricalcium Phosphate - TCP

6. Dicalcium Phosphate - DCP

7. Feed Conversion Ratio - FCR

8. Body Weight Gain - BWG

9. Feed Intake - FI

10. Live Weight Gain - LWG

11. Apparent Ileal Amino Acid Digestibility - AIAAD

12. Inorganic Phosphate Source - IPS

13. California Pellet Mill - CPM

14. West Virginia University - WVU

\section{CHAPTER 3:}

1. Phosphorus $-\mathrm{P}$

2. Calcium $-\mathrm{Ca}$

3. Optiphos Plus - OP

4. Quantum Blue - QB

5. Live Weight Gain - LWG

6. Feed Intake - FI

7. Feed Conversion Ratio - FCR

8. Positive Control - PC

9. Negative Control- NC

10. Non-phytate Phosphorus - nPP

11. Titanium dioxide $-\mathrm{TiO}_{2}$

12. California Pellet Mill - CPM

13. Crude Protein - CP

14. Pellet Durability Index - PDI

15. Bird Weight - BW

16. Apparent Ileal Ca Digestibility AID Ca

17. Apparent Ileal P Digestibility - AID $\mathrm{P}$ 


\section{CHAPTER 1: LITERATURE REVIEW}

\section{PHOSPHORUS AND PHYTATE}

Phosphorus $(\mathbf{P})$ is an essential mineral for the growth and health of both mammals and avians (Viveros et al. 2002). P plays a role in cellular physiology, aids in the formation of the skeletal system, and is a key component of nucleic acids as well as phospholipid membranes (Viveros et al. 2002; Drezner, 2002). Modern meat type chickens, known as broilers, are particularly sensitive to $\mathrm{P}$ due to their lack of a $\mathrm{P}$ storage mechanism and their rapid growth (Denbow et al. 1995).

In the United States, commercial poultry are primarily fed corn and soybean-based diets. According to Vats and Banerjee (2004), phytic acid comprises 1-5\% by weight of cereals, legumes, and oil seeds, and thus, is the major storage form of P. Reddy et al. (1982) found that as much as $50-85 \%$ of the $\mathrm{P}$ in plants is bound in the phytic acid form. Phytic acid (myoinositol 1,2,3,4,5,6-hexakis dihydrogen phosphate or IP6) also tends to chelate with other minerals and proteins and is then referred to as phytate (Selle et al. 2000). Monogastric animals such as poultry are unable to release $\mathrm{P}$ and other minerals from phytic acid due to the lack of the enzyme phytase, rendering these minerals unavailable (Cheryan and Rackis, 1980; Posternak, 1904; Jiang et al. 2013). Therefore, a majority of the phytate bound P ends up in the excreta. Few plants, such as wheat and barley, are rich in phytase; however, these phytases do not perform well in acidic environments below a pH of 4 such as found in the upper gastrointestinal (GI) tract of poultry (Cao et al. 2007).

Phytate is regarded as an antinutritional factor to monogastrics (Selle et al. 2000; Pen et al. 1993). Antinutritional factors decrease or inhibit the digestibility of nutrients; however, antinutritional factors are beneficial to plants, by offering protection from molds, bacteria, 
insects, and birds (Savelkoul et al. 1992; Ryan, 1973). Gupta and Venkitasubramian (1975) suggested that due to the binding of phytic acid to zinc within soybeans, aflatoxin producing molds are unable to colonize and reproduce. Aflatoxins are a significant concern in commercial poultry feed production; therefore, this blocking ability is desirable. The charged phosphate groups on phytate possess a chelating ability which has the potential to form complexes with protein and individual amino acids (Selle et al. 2000). Chelation occurs when chelation agents bind with metal ions or proteins to form ring structures, which are then removed from the body in the excreta (Flora and Pachauri, 2010). Phytic acid is described by Nolan and coauthors (1987) as being ionized, and thus, tends to interact with proteins and metal ions. Others have recognized phytic acid's ability to bind to a number of metals, such as calcium, zinc, and iron. This renders these minerals unavailable for absorption within the digestive tract of monogastrics (Selle et al. 2000; Pen et al. 1993; Nakano et al. 2001).

$\mathrm{P}$ was commonly supplemented to poultry feed by the addition of inorganic forms to meet $\mathrm{P}$ demand. Dicalcium, tricalcium, and monocalcium $\mathrm{P}$ are currently common feed additives to supplement $\mathrm{P}$ in the diet; however, inorganic $\mathrm{P}$ is the third most expensive ingredient in poultry diets (Kiarie et al. 2013). There is also concern over the environmental impact associated with inorganic P supplementation. Poultry litter spread on crop fields containing large concentrations of phytate bound P that can lead to runoff and eutrophication (Jiang et al. 2013; Biehl and Baker, 1996). The bioavailability of inorganic forms of $\mathrm{P}$ is also less than $100 \%$ resulting in increased $\mathrm{P}$ present in the excreta. Due to the unavailability of this vital mineral in major components of poultry diets as well as the high cost and environmental concerns of inorganic $\mathrm{P}$, it was advantageous for producers to find an alternative source of bioavailable P. Additionally, as the human population increases exponentially and people search for a healthier source of protein, the 
demand for chicken also grows. The demand for chicken meat in the United States has steadily increased since the 1960's, while the demand for red meat has remained stable (National Chicken Council), therefore, creating a situation where a more efficient form of $\mathrm{P}$ is necessary to meet the needs of the population.

\section{FEED ADDITIVES}

Feed manufacturers add a variety of products to poultry diets. Enzymes are added in order to negate the effects of antinutritional factors found in feed ingredients. However, many products are designed to aid in the feed manufacture process which in turn, may generate higher quality feed while decreasing production costs. Feed mill throughput, or how quickly feed is moved through the system as ingredients are mixed and subsequently pelleted, is increased while motor load is decreased by certain properties of some feed additives.

\section{Phytase}

Enzymatic catalysts act by increasing the rate at which a chemical reaction occurs and may be a method for increasing available P. Phytase is an exogenous enzyme added to poultry diets that works by hydrolyzing phytin and releasing $\mathrm{P}$ and inositol for use by the animal (Pen et al. 1993). Dietary forms of phytase have been sourced from various plants and microorganisms. Currently, genes are encoded from select mold and fungi that possess high phytase activity (Pen et al. 1993; Peers, 1953), and then the phytase genes are often expressed in yeast or select bacteria (Augspurger et al. 2003).

Phytase has become an invaluable addition to poultry diets by reducing feed cost. Enzymatic activity of phytase is measured in phytase units (FTU). One FTU is defined as the quantity of enzyme required to release one $\mu \mathrm{mol}$ of inorganic $\mathrm{P}$ per minute from $5.1 \mathrm{mM}$ sodium 
phytate at $\mathrm{pH} 5.5$ at $37^{\circ} \mathrm{C}$ (Denbow et al. 1995). Other common abbreviations for phytase units are U, FYT, and PU. It is important to consider the characteristics of phytase products, as the enzymes differ depending on the source. This can have a negative impact on bird performance and thus, enzyme comparisons can help identify the strengths and weaknesses of different sourced enzymes.

Monogastric animals have been found to express varying amounts of phytase activity within their GI tract. The phytase activity within the digestive tract of numerous animals has been investigated and well-documented. Patwardhan (1937) found evidence that albino rats possess little intestinal phytase activity. Further research has supported this claim, although the extent of the phytase activity depended on the $\mathrm{pH}$ of the intestinal brush border membrane (Nakano et al. 2001). Phytase activity has also been discovered in calves and swine; however, insufficient activity has been found in poultry (Bitar and Reinhold, 1972; Spitzer and Phillips, 1945).

The effects of phytase on poultry at graded doses has been the focus of much research for decades. Manufacturers of phytase often recommend doses of 1,000 to 1,500 FTU/kg for broiler chickens (ABVista, Woodstock Ct, Marlborough; 36; Huvepharma, Sofia, Bulgaria); however, many studies have investigated the effects of lower and higher doses. Boling and coauthors (2000) found that single comb white leghorn hens fed a corn and soybean-based diet in the absence of exogenous phytase exhibited a decrease in body weight and egg production, and increased morbidity when compared to supplemented hens. Additionally, the results of this experiment indicated that hens supplemented with at least $100 \mathrm{FTU} / \mathrm{kg}$ phytase were healthy and performed adequately. It is still commonly accepted that a low dose of $500 \mathrm{FTU} / \mathrm{kg}$ phytase is necessary for sufficient performance (Wealleans et al. 2016). However, recent studies have 
suggested that higher doses result in improved bird performance including feed conversion ratio (FCR), body weight gain (BWG), feed intake (FI), and tibia ash (Gautier et al. 2018; Broch et al. 2018). Currently, focus is on achieving optimal performance of poultry rather than adequate performance, in order to meet the high demands of the consumer.

Wealleans and coauthors (2016) investigated the effects of higher doses of phytase on poultry and supplemented turkey poult diets with analyzed values of 345, 690, 1,035, and 1,380 FTU/kg phytase to 21 days of age. Results showed that 1035 FTU/kg phytase yielded the highest growth, with a $20 \%$ increase in BWG compared to the negative control diet lacking phytase. The authors concluded that the amount of ileal inorganic $\mathrm{P}$ released in response to varying doses of phytase is curvilinear, and that doses above 500 FTU are beneficial. The study also determined that overdosing phytase may be more cost effective than underdosing, depending on price and source of the phytase product, with a savings of \$4.26/ton from inorganic P substitution alone. In another study, Simons and coauthors (1990) increased the upper dose, and supplemented broiler chickens with gradient doses of phytase from 250 to 2,000 FTU/kg in a pelleted feed form to day 24 and noted that with each increasing dose the apparent digestibility of P and Calcium (Ca) was improved, in addition to less $\mathrm{P}$ in the excreta. Furthermore, the study found a significant improvement in FCR with concentrations of 1,500 and 2,000 FTU/kg phytase, with 24d old birds supplemented with 2,000 FTU/kg exhibiting a FCR of 1.50, compared to a lower dose of 250 FTU/kg resulting in a FCR of 1.59 .

Other researchers have found similar improvements in bird performance in response to phytase supplementation. Farrell and coauthors (1993) fed doses of phytase to broiler chicks and ducklings at $750 \mathrm{FTU} / \mathrm{kg}$ for 18 days and $850 \mathrm{FTU} / \mathrm{kg}$ for 17 days, respectively and observed an improvement in FCR from 1.49 to 1.44 , an $18 \%$ increase in P retention, increased FI, increased 
nitrogen retention, and increased tibia ash percentage in the broiler chicks. Ducklings displayed similar improvements, an increase in FI, growth rate, $\mathrm{P}$ retention, and tibia ash. The increase in tibia ash may be explained by the role of $\mathrm{P}$ in bone development as well as phytases ability to increase the availability of both $\mathrm{P}$ and $\mathrm{Ca}$. These findings suggest that the digestibility and/or availability of nutrients is improved with the addition of phytase. These findings have been supported by other studies (Kornegay et al. 1996; Denbow et al. 1998).

The aforementioned studies were conducted over relatively short periods of time. Industries commonly depopulate when birds reach 6-8 weeks of age. However, there may be value in performing a longer study to determine if beneficial effects on bird performance continue or if performance slows. Similarly, some authors found no change in FCR in response to phytase addition (Viveros et al. 2002; Huff et al. 1998). This appeared to correlate with the age of the birds, with younger birds such as broilers experiencing greater benefits from a higher dose of phytase (Broch et al. 2018). This may be attributed to an increase in BWG and FI as the birds age. It was also suggested that as birds age, they can compensate for deficiencies to some extent. There are also other independent factors to consider, such as the source of soybean meal used. Soybean meal contains varying amounts of trypsin inhibitor which may negatively affect FCR (Bergeron et al. 2018). Proper heat should be applied to soybean meal in order to ensure destruction of trypsin inhibitor. Conversely, high temperatures can have an adverse effect on certain phytase products.

\section{Phytase Type}

There are numerous commercially available phytase products on the market. Many of which are derived from different microorganisms and display different characteristics. Phytase is a protein, and therefore, it is susceptible to hydrolysis by endogenous proteases found within the 
animals' digestive tract (Dersjant-Li et al. 2015). Different sources of phytase resist degradation by proteases more efficiently than others, and thus, should be considered when choosing a product. Kumar and coauthors (2003) examined the reaction of three different phytases incubated in a buffer containing protease. Escherichia coli $(\boldsymbol{E}$. coli) was shown to have a higher resistance than Peniophora lycii and Aspergillus niger (A. niger). Huang and coauthors (2008) examined phytases sourced from different microorganisms using incubation in simulated gastric fluid. The study found that phytase sourced from Yersinia rohdei resisted destruction by proteases and released two to ten times more inorganic $\mathrm{P}$ than some major commercial phytases derived from $E$. coli and A. niger. Further research may indicate microorganisms that are more resistant to hydrolysis by proteases.

Second, different sources of phytase function at different $\mathrm{pH}$ ranges. The enzyme must not be degraded within the GI of the animal (Mushinge, 2015). Previous studies have successfully modified the optimum $\mathrm{pH}$ range of certain phytases through chemical modification. Rashid H. and Siddiqui S. (1998) successfully reduced the optimum $\mathrm{pH}$ of $A$. Niger from $\mathrm{pH} 4.5$ to $\mathrm{pH} 2.5$ through modification of surface carboxyl groups. In a similar study, Fang and Ford (1998) increased the $\mathrm{pH}$ of Aspergillus awamori glucoamylase by 0.8 units through the manipulation of hydrogen bonds via site-directed mutagenesis. Therefore, producers must consider the $\mathrm{pH}$ range that the enzyme will be exposed to when deciding which product to incorporate into the diet.

Broiler feed is almost exclusively pelleted, thereby subjecting the feed to high temperatures. Phytase derived from different microorganisms offer varying degrees of thermostability (Goncalves et al. 2015). This is an important factor to consider if the feed is to be subjected to high temperatures during the pelleting process. Storage of feed post pelleting in 
higher temperatures can also cause denaturation of phytase. Many companies have manufactured a heat tolerant coating around the phytase to preserve the enzyme activity (Goncalves et al. 2015). Additionally, phytases can be chemically modified to withstand higher temperatures. Kim and Lei (2008) successfully improved the thermostability of E. coli by $20 \%$ through error prone polymerase chain reaction (PCR) mutagenesis. It should be noted that phytase can be incorporated either at the mixer, prior to pelleting, or sprayed on post-pelleting. Mixer added phytase in the form of a powder or granules is generally the most common method due to the extra investment associated with post-pellet sprays (Slominski, et al. 2007). In addition, a reduction in phytase activity may occur when pellets come into contact with surfaces during transportation due to the vulnerable location of phytase on the surface of the pellets (Slominski, et al. 2007). Due to the disadvantages of post-pelleting application methods, there is a need for further research into the performance and comparison of different heat stable phytase products.

\section{Feed Mill Production Rate}

Feed manufacture accounts for the majority of the cost associated with poultry production (Cutlip et al. 2008). Therefore, poultry nutritionists are continuously searching for new methods to reduce the cost of feed production while maintaining nutrient density. Increasing the rate of feed production rate may reduce production costs by increasing mill capacity while decreasing mill energy usage and motor load (Boltz et al. 2021). The increase in feed production rate can be achieved using various feed ingredients and additives.

Rock phosphate is commonly added to poultry diets and can have a scouring effect on the pellet mill die, thereby increasing production rate. Furthermore, different sources of rock phosphate affect throughput at varying degrees. According to Boltz and coauthors (2021) corn, soybean, and dried distillers grains with solubles based diets containing tricalcium phosphate 
presented with a production rate of 1.150 metric ton per hour (MT/hr), whereas diets containing dicalcium phosphate had a production rate of $1.019 \mathrm{MT} / \mathrm{hr}$. In addition, there are feed additives that may increase mill throughput, mitigating the need for costly inorganic phosphate ingredients and reducing the negative environmental impact associated with them.

\section{AMINO ACIDS/PROTEINS}

When nutritionists speak of amino acid digestibility and availability, they are often referring to the extent to which the amino acid has been converted into forms suitable for protein synthesis (Batterham, 1992). Balance assays are used to determine digestibility (Parsons, 1996). However, it is possible for an amino acid to be digested but not utilized due to the form, thus it is not available to the bird (Batterham, 1992).

When formulating a diet, it is vital to consider loss of amino acid digestibility and availability due to the feed manufacturing process. Processes which add heat to the feed, such as pelleting, are particularly susceptible to amino acid degradation (Parsons, 1996). Lysine and cystine are especially sensitive to degradation due to their susceptibility to Maillard browning reactions (Parsons, 1996; del Cueto et al. 1960). The Maillard browning reaction is defined as the interaction of amino compounds, including all amino acids comprising natural proteins, and reducing sugars during thermal processing and storage of foods (Ashoor and Zent, 1984). Excessive friction and pressure applied at the pellet die can cause a loss of protein confirmation, leading to the exposure of the inward oriented hydrophobic amino acids and thus reducing protein solubility and subsequent digestibility. Furthermore, the moisture content of the feed and ingredients can impact protein denaturation (Boroojeni et al. 2016). Higher moisture content of feed ingredients as well as adding more steam to mash during steam conditioning can increase the protein denaturation temperature. The concentration of salt in the diet also affects protein 
digestibility. Salt can increase the protein denaturation temperature via a stabilizing effect (Damodaran, 1988). Lastly, the type of protein can affect the extent of protein denaturation. In a study conducted by Kitabatake and coauthors (1989) it was found that the denaturation temperature of wheat gluten was lower than that of corn gluten.

To account for amino acid losses that occur during feed manufacturing and to supplement naturally occurring deficiencies in the diet, manufacturers add synthetic crystalline amino acids to poultry diets. Crystalline amino acids are nearly 100\% digestible (Selle et al. 2020); however, they are one of the most expensive feed ingredients in broiler diets. It is thus advantageous to limit their addition to only what is utilized by the bird. Despite being economically unfavorable, many broiler industries over formulate diets for essential amino acids. This is due to a lack of research conducted on amino acid destruction by heat. The few studies conducted have demonstrated that exposing amino acids, namely lysine, to increasing temperatures results in a decrease in digestibility (Boltz et al. 2020; Loar et al. 2014). Rutherford and Moughan (1997) found such results from heating field peas, noting that as the temperature increased beyond $135^{\circ} \mathrm{C}$ for 15 minutes, the total lysine and lysine digestibility decreased by $53 \%$ and $28 \%$, respectively. In the search for a more economically favorable method of meeting the amino acid requirements of broilers, researchers have investigated the effects of phytase on amino acid digestibility. In a similar study, Fontaine and coauthors (2007) observed a 10-20\% loss of lysine when soybean meal was heated to $135^{\circ} \mathrm{C}$ in an autoclave. The authors also noted that up to $67 \%$ reactive lysine may be lost when overheated.

Studies have found that the addition of exogenous phytase to feed increases ileal amino acid digestibility. Ravindran et al. (1999) fed broiler chicks several diets, either containing 1,200 FTU/kg phytase or no added phytase. The researchers reported a significant increase in ileal 
amino acid digestibility in birds supplemented with phytase in contrast to birds receiving no phytase. In another study, it was found that protein digestibility coefficients were increased by $6.08 \%$ in response to the addition of 500 FTU/kg phytase (Truong et al. 2017). This is suggested be due to phytate chelating with proteins and amino acids as previously mentioned, and rendering amino acids unavailable for utilization by the animal.

\section{FEED FORM}

Feed processing includes the treatment of a feed, either physical, chemical, or thermal, prior to feeding to animals (Thomas and Van der Poel, 1996). There are several different processing methods to prepare poultry feed. Mash is a complete diet with uniform texture and is designed to reduce separation of feed by the birds (Jahan et al. 2006). To prepare mash, many of the ingredients, most notably grains, are first finely ground, typically utilizing either a hammer or roller mill (Abdollahi et al. 2013). The remaining ingredients are then mixed thoroughly with the ground ingredients. The major drawback of mash is that feed waste is typically high. In addition, birds often sort out larger particles of corn and more palatable pieces, leaving the less desirable fines. There is an economic advantage of feeding mash, however. Mash is considerably cheaper due to the additional costly equipment required for pelleting, such as a boiler and roller and die pellet press, which in turn requires more energy and labor. Lv and coauthors (2015) stated that it costs roughly $10 \%$ more to pellet feed. It is imperative to take into consideration the costs associated with feed preparation, as feed accounts for roughly $60-65 \%$ of the total cost of broiler production (Sena et al. 2015). 


\section{Pellet manufacturing}

Mash may be sent for further processing in order to produce pellets or crumbles. Crumbles are simply pellets that have been ground to achieve a smaller particle size, normally for young birds that are unable to swallow large pellets. A majority of broilers in the United States consume pelleted feed. Pellets are prepared by first moistening the mash while raising mash temperature, typically through steam conditioning with average conditioning temperatures of 80 to $90^{\circ} \mathrm{C}$ (Calet, 1965). This temperature may vary depending on ambient temperatures. Temperatures may also vary depending on the lipid and starch content of the feed, as these act as lubricants and alter the amount of frictional heat that is generated. The feed may reach higher temperatures of up to $200^{\circ} \mathrm{C}$ during the extrusion process when feed is placed under high pressure as it is formed into a compact pellet (Boroojeni et al. 2016). Upon heating, the moistened mash may enter a hygieniser, where the feed is subjected to jacketed heat for a predetermined amount of time. From the hygieniser, the feed will be sent through a roller and die pellet press where it will be forced through the die, shaped, and cut in a uniform manner (Thomas and Van der Poel, 1996). Lastly, the pellets pass through a cooler upon which they can be loaded for transportation. The particles become more solid and resistant to breakage as the pellets cool and moisture bridges shrink (Thomas and Van der Poel, 1996). This ensures that the pellets will hold up during handling and transport, increasing pellet durability index (PDI).

\section{Pellets versus mash in bird performance}

Aside from the high cost of production and possible protein destruction, pellets have been shown to be superior to mash in various ways when fed to poultry. Studies have consistently discovered that feeding a pelleted diet increases the growth rate and feed utilization of broilers. Sell and Thompson (1965) compared the outcome of feeding mash and pellets, either low fat or 
with a $10 \%$ fat inclusion. The authors discovered that of the birds fed the low-fat diet, those consuming pellets demonstrated an increase in growth rate, carcass fat, and feed and energy utilization in relation to chickens fed mash. These effects were not observed in the groups fed the diet containing $10 \%$ fat, however. These finding are consistent with those of Hamilton and Proudfoot (1995) who fed five diets, each consisting of different particle sizes, and found that a larger particle size generated more favorable results in 42-day old broilers. The study observed an increase in growth rate and monetary returns. The authors also noted a significant decrease in FCR unlike the study by Hamilton and Proudfoot (1995). Smith (1985) offers a possible explanation for the unexpected effect on FCR. Smith suggested that the steam added during the pelleting process partially gelatinizes the starches from cereal grain components of diets, increasing the rate of enzymatic hydrolysis and thus, increasing digestibility. The effect on FCR of poultry when fed pellets remains mixed; however, many studies agree that pellets increase feed efficiency, feed utilization, and growth rate (Lv et al. 2015; Proudfoot and Hulan, 1982).

Pellets have also been shown by some studies to increase the incident of sudden death syndrome (SDS) in broilers (Proudfoot and Hulan, 1982). This is likely due to the increase in growth rate and FI. An increase in feed density is likely responsible for the increase in FI (Heywang and Morgan, 1944). Hussar and Robblee (1962) noted that pelleting feed increased its density by $24 \%$. Despite the increase in mortality in the above experiment, monetary returns were greater for the broilers fed the pelleted diet rather than the mash. In contrast, other studies have shown no difference in mortality between mash and pellet fed broilers (Jahan et al. 2006). 


\section{References}

1. Abdollahi, M. R., V. Ravindran, and B. Svihus. 2013. Pelleting of broiler diets: An overview with emphasis on pellet quality and nutritional value. Anim. Feed. Sci. Tech. 179:1-23.

2. ABVista, Woodstock Ct, Marlborough.

3. Ashoor, S. H., and J. B. Zent. 1984. Maillard browning of common amino acids and sugars. J. Food. Sci. 49:1206-1207.

4. Augspurger, R., D. M. Webel, X. G. Lei, D. H. Baker. 2003. Efficacy of an E. coli phytase expressed in yeast for releasing phytate-bound phosphorus in young chicks and pigs, J. Anim. Sci. 81:474-483

5. Batterham, E. S. 1992. Availability and utilization of amino acids for growing pigs. Nutr Res Rev. 5:1-18.

6. Bergeron, A. N., J. W. Boney, and J. S. Moritz. 2018. The effects of diet formulation and thermal processes associated with pelleting on 18-day broiler performance and digestible amino acid concentration. J. Appl. Poultry. Res. 27:540-549.

7. Biehl, R. R., and D. H. Baker. 1996. Efficacy of supplemental $1 \alpha$-hydroxycholecalciferol and microbial phytase for young pigs fed phosphorus-or amino acid-deficient cornsoybean meal diets. J. Anim. Sci. 74:2960-2966.

8. Bitar, K., and J. G. Reinhold. 1972. Phytase and alkaline phosphatase activities in intestinal mucosae of rat, chicken, calf, and man. BBA-Protein Struc M, 268:442-452.

9. Boling, S. D., M. W. Douglas, R. B. Shirley, C. M. Parsons, and K. W. Koelkebeck. 2000. The effects of various dietary levels of phytase and available phosphorus on performance of laying hens. Poult. Sci. 79:535-538.

10. Boltz, T. P., J. Ferrel, K. M. Bowen, K. L. Harding, V. E. Ayres, and J. S. Moritz. 2021. The effect of a dacitic tuff breccia (Azomite ${ }^{\circledR}$ ) in corn, soybean, and DDGS based diets that vary in inorganic phosphate source on pellet mill production rate and pellet quality. $\mathrm{J}$. Appl. Poult. Res. 30:100147

11. Boltz, T. P., N. E. Ward, V. E. Ayres, A. E. Lamp, and J. S. Moritz. 2020. The effect of varying steam conditioning temperature and time on pellet manufacture variables, true amino acid digestibility, and feed enzyme recovery. J. Appl. Poult. Res. 29:328-338.

12. Boroojeni, F. G., B. Svihus, H. G. von Reichenbach, and J. Zentek. 2016. The effects of hydrothermal processing on feed hygiene, nutrient availability, intestinal microbiota and morphology in poultry-A review. Anim. Feed. Sci. Tech. 220:187-215.

13. Broch, J., R. V. Nunes, C. Eyng, G. M. Pesti, C. de Souza, G. G. Sangalli, V. Fascina, and L. Teixeira. 2018. High levels of dietary phytase improves broiler performance. Anim. Feed. Sci. Tech. 244:56-65.

14. Calet, C. 1965. The relative value of pellets versus mash and grain in poultry nutrition. World Poultry Sci. J. 21:23-52.

15. Cao, L., W. Wang, C. Yang, Y. Yang, J. Diana, A. Yakupitiyage, Z. Luo, and D. Li. 2007. Application of microbial phytase in fish feed. Enzyme. Microb. Tech. 40:497-507.

16. Cheryan, M., and J. J. Rackis. 1980. Phytic acid interactions in food systems. Crit. Rev. Food. Sci. 13:297-335. 
17. Cutlip, S. E., J. M. Hott, N. P. Buchanan, A. L. Rack, J. D. Latshaw, and J. S. Moritz. 2008. The effect of steam-conditioning practices on pellet quality and growing broiler nutritional value. J. Appl. Poult. Res. 17:249-261.

18. Damodaran, S. 1988. Refolding of thermally unfolded soy proteins during the cooling regime of the gelation process: effect on gelation. J. Agr. Food. Chem. 36:262-269.

19. del Cueto, A. G., W. H. Martinez, and V. L. Frampton. 1960. Heat effects on peas, effect of autoclaving on the basic amino acids and proteins of the chick pea. J. Agr. Food. Chem. 8:331-332.

20. Denbow, D. M., V. Ravindran, E. T. Kornegay, Z. Yi, and R. M. Hulet. 1995. Improving phosphorus availability in soybean meal for broilers by supplemental phytase. Poult. Sci. 74: 1831-1842.

21. Denbow, D.M., E. A. Grabau, G. H. Lacy, E. T. Kornegay, D. R. Russell, and P. F. Umbeck. 1998. Soybeans transformed with a fungal phytase gene improve phosphorus availability for broilers. Poult. Sci. 77:878-881.

22. Dersjant-Li, Y., A. Awati, H. Schulze, and G. Partridge. 2015. Phytase in non-ruminant animal nutrition: a critical review on phytase activities in the gastrointestinal tract and influencing factors. J. Sci. Food. Agr. 95:878-896.

23. Drezner, Marc K. 2002. Phosphorus homeostasis and related disorders. Principles of bone biology. Academic Press. 321-338.

24. Fang, T. Y., and C. Ford. 1998. Protein engineering of Aspergillus awamori glucoamylase to increase its pH optimum. Protein. eng. 11:383-388.

25. Farrell, D.J., E. Martin, J. J. Du Preez, M. Bongarts, M. Betts, A. Sudaman, and E. Thomson. 1993. The beneficial effects of a microbial feed phytase in diets of broiler chickens and ducklings. J. Anim. Physiol. An. N. 69:278-283.

26. Flora, S. J., and V. Pachauri. 2010. Chelation in metal intoxication. Int. J. Env. Res. Pub. He. 7:2745-2788.

27. Fontaine, J., U. Zimmer, P. J. Moughan, and S. M. Rutherfurd. 2007. Effect of heat damage in an autoclave on the reactive lysine contents of soy products and corn distillers dried grains with solubles. Use of the results to check on lysine damage in common qualities of these ingredients. J. Agr. Food. Chem. 55:10737-10743.

28. Gautier, A. E., C. L. Walk, and R. N. Dilger. 2018. Effects of a high level of phytase on broiler performance, bone ash, phosphorus utilization, and phytate dephosphorylation to inositol. Poult. Sci. 97:211-218.

29. Gonçalves, M. A., S. S. Dritz, M. D. Tokach, J. M. DeRouchey, J. C. Woodworth, and R. D. Goodband. Comparing different phytase sources for pigs. Late gestation lysine and energy effects in sows and dose-responses to tryptophan and valine in finishing pigs. 2015. 216.

30. Gupta, S. K., and T. A. Venkitasubramanian. 1975. Production of aflatoxin on soybeans. Appl. microbiol. 29:834-836.

31. Hamilton, R. M. G., and F. G. Proudfoot. 1995. Ingredient particle size and feed texture: effects on the performance of broiler chickens. Anim Feed Sci Tech. 51:203-210.

32. Heywang, B. W., R. B. Morgan. 1944. A comparison of a pelleted and unpelleted allmash diet for growing chickens. Poult. Sci. 23:16-20. 
33. Huang, H., H. Luo, Y. Wang, D. Fu, N. Shao, G. Wang, P. Yang, and B. Yao. 2008. A novel phytase from Yersinia rohdei with high phytate hydrolysis activity under low $\mathrm{pH}$ and strong pepsin conditions. Appl. Microbiol. Biot. 80:417.

34. Huff, W. E., P. A. Moore Jr, P. W. Waldroup, A. L. Waldroup, J. M. Balog, G. R. Huff, N. C. Rath, N. C. Daniel, and V. Raboy. 1998. Effect of dietary phytase and high available phosphorus corn on broiler chicken performance. Poult. Sci. 77:1899-1904.

35. Hussar, N., and A. R. Robblee. 1962. Effects of pelleting on the utilization of feed by the growing chicken. Poult. Sci. 41:1489-1493.

36. Huvepharma, Sofia, Bulgaria

37. Jahan, M. S., M. Asaduzzaman, and A. K. Sarkar. 2006. Performance of broiler fed on mash, pellet and crumble. Int. J. Poult. Sci. 5:265-270.

38. Jiang, X. R., F. H. Luo, M. R. Qu, V. Bontempo, S. G. Wu, H. J. Zhang, H. Y. Yue, and G. H. Qi. 2013. Effects of non-phytate phosphorus levels and phytase sources on growth performance, serum biochemical and tibia parameters of broiler chickens. Ital. J. Anim. Sci. 12:e60.

39. Kiarie, E., L. F. Romero, and C. M. Nyachoti. 2013. The role of added feed enzymes in promoting gut health in swine and poultry. Nutr. Res. Rev. 26:71-88.

40. Kim, M. S., and X. G. Lei. 2008. Enhancing thermostability of Escherichia coli phytase AppA2 by error-prone PCR. Appl. Microbiol. Biot. 79:69-75.

41. Kitabatake, N., M. Tahara, E. Doi. 1989. Denaturation Temperature of Soy Protein under Low Moisture Conditions. Agric. Biol. Chem. 53:1201-1202.

42. Kornegay, E.T., D. M. Denbow, Z. Yi, and V. Ravindran. 1996. Response of broilers to graded levels of microbial phytase added to maize-soyabean-meal-based diets containing three levels of non-phytate phosphorus. Brit. J. Nutr. 75:839-852.

43. Kumar, V., A. Miasnikov, J. S. Sands, and P. H. Simmins. 2003. In vitro activities of three phytases under different $\mathrm{pH}$ and protease challenges. APSA Conf. P. 164-164.

44. Loar II, R. E., K. G. S. Wamsley, A. Evans, J. S. Moritz, and A. Corzo. 2014. Effects of varying conditioning temperature and mixer-added fat on feed manufacturing efficiency, 28-to 42-day broiler performance, early skeletal effect, and true amino acid digestibility. J. Appl. Poult. Sci. 23:444-455.

45. Lv, M., L. Yan, Z. Wang, S. An, M. Wu, and Z. Lv. 2015. Effects of feed form and feed particle size on growth performance, carcass characteristics and digestive tract development of broilers. Anim. Nutr. 1:252-256.

46. Mushinge, B. M. 2015. Evaluation of various Phytase enzymes for application in broiler feeding (Doctoral dissertation, Stellenbosch: Stellenbosch University).

47. Nakano, Y., T. Kawamoto, and Y. Takano. 2001. Phosphatase activities of rat intestinal enterocytes and their relation to diverse luminal $\mathrm{pH}$, with special references to the possible localization of phytase along the brush border membrane. Arch. Histol. Cytol. 64:483-492.

48. Nakano, Y., T. Kawamoto, and Y. Takano. 2001. Phosphatase activities of rat intestinal enterocytes and their relation to diverse luminal $\mathrm{pH}$, with special references to the possible localization of phytase along the brush border membrane. Arch. Histol. Cytol, 64:483-492. 
49. National Chicken Council.

50. Nolan, K. B., P. A. Duffin, and D. J. McWeeny. 1987. Effects of phytate on mineral bioavailability. In vitro studies on $\mathrm{Mg} 2+, \mathrm{Ca} 2+, \mathrm{Fe} 3+, \mathrm{Cu} 2+$ and $\mathrm{Zn} 2+($ also $\mathrm{Cd} 2+)$ solubilities in the presence of phytate. J. Sci. Food. Agr. 40:79-85.

51. Parsons, C. M. 1996. Digestible amino acids for poultry and swine. Anim. Feed. Sci. Tech. 59:147-153.

52. Patwardhan, V. N. 1937. The occurrence of a phytin-splitting enzyme in the intestines of albino rats. Biochem. J. 31:560-564.

53. Peers, F.G. 1953. The phytase of wheat. Biochem. J. 53:102-110.

54. Pen, J., T. Verwoerd, P. van Paridon, R. F. Beudeker, P. J. M. Van Den Elzen, K. Geerse, J. D. Van Der Klis, H. A. J. Versteegh, A. J. J. Van Oooyen, and A. Hoekema. 1993. Phytase-containing Transgenic Seeds as a Novel Feed Additive for Improved Phosphorus Utilization. Nat. Biotechnol. 11:811-814.

55. Posternak S. Organic phosphorus compound and process of making same. U.S. Patent No. 754,803. Washington, DC: U.S. Patent and Trademark Office. 1904.

56. Proudfoot, F. G., H. W. Hulan, and K. B. Mc Rae. 1982. The effect of crumbled and pelleted feed on the incidence of sudden death syndrome among male chicken broilers. Poult. Sci. 61:1766-1768.

57. Rashid, M. H., and K. S. Siddiqui. 1998. Carboxy-group modification: high-temperature activation of charge-neutralized and charge-reversed $\beta$-glucosidases from Aspergillus niger. Biotechnol. Appl. Bioc. 27:231-237.

58. Ravindran, V., S. Cabahug, G. Ravindran, and W. L Bryden. 1999. Influence of microbial phytase on apparent ileal amino acid digestibility of feedstuffs for broilers. Poult. Sci. 78:699-706.

59. Reddy, N. R., S. K. Sathe, and D. K. Salunkhe. 1982. Phytates in legumes and cereals. Adv. Food. Res. 28:1-92.

60. Rutherfurd, S. M., and P. J. Moughan. 1997. Application of a new method for determining digestible reactive lysine to variably heated protein sources. J. Agr. Food. Chem. 45:1582-1586.

61. Ryan, C. A. 1973. Proteolytic enzymes and their inhibitors in plants. Ann. Rev. Plant. Physio. 24:173-196.

62. Savelkoul, F. H. M. G., A. F. B. Van der Poel, and S. Tamminga. 1992. The presence and inactivation of trypsin inhibitors, tannins, lectins and amylase inhibitors in legume seeds during germination. A review. Plant. Food. Hum. Nutr. 42:71-85.

63. Sell, J. L., and O. J. Thompson. 1965. The effects of ration pelleting and level of fat on the efficiency of nutrient utilisation by the chicken. Brit. Poult. sci. 6:345-354.

64. Selle, P. H., J. C. de Paula Dorigam, A. Lemme, P. V. Chrystal, and S. Y. Liu. 2020. Synthetic and Crystalline Amino Acids: Alternatives to Soybean Meal in Chicken-Meat Production. Animals: an open access journal from MDPI. 10:729.

65. Selle, P. H., V. Ravindran, A. Caldwell, and W. L. Bryden. 2000. Phytate and phytase: consequences for protein utilisation. Nutr. Res. Rev. 13:255-278.

66. Sena, S., L. Sena, A. Hoda, and M. Nikolla. 2014. Broiler performance fed on mash vs. pellets. Albanian J. Agric. Sci. 353. 
67. Simons, P. C. M., H. A. Versteegh, A. W. Jongbloed, P.A. Kemme, P. Slump, K. D. Bos M. G. E. Wolters, R. F. Buedeker, and G. J. Verschoor. 1990. Improvement of phosphorus availability by microbial phytase in broilers and pigs. Brit. J. Nutr. 64:525540.

68. Slominski, B. A., T. Davie, M. C. Nyachoti, and O. Jones. 2007. Heat stability of endogenous and microbial phytase during feed pelleting. Livest. Sci. 109:244-246.

69. Smith, O. B. 1985. Extrusion cooking systems. In Feed Manufacturing Technology III (pp. 195-204). American Feed Association, Inc Arlington, VA.

70. Spitzer, R. R., and P. H. Phillips. 1945. Enzymatic relationships in the utilization of soybean oil meal phosphorus by the rat: Two figures. J. Nutr. 30:183-192.

71. Thomas, M. A. F. B., and A. F. B. Van der Poel. 1996. Physical quality of pelleted animal feed 1. Criteria for pellet quality. Anim. Feed. Sci. Tech. 61:89-112.

72. Truong, H. H., S. Yu, A. F. Moss, G. G. Partridge, S. Y. Liu, and P. H. Selle. 2017. Phytase inclusions of 500 and 2000 FTU/kg in maize-based broiler diets impact on growth performance, nutrient utilisation, digestive dynamics of starch, protein $(\mathrm{N})$, sodium and IP6 phytate degradation in the gizzard and four small intestinal segments. Anim. Feed. Sci. Tech. 223:13-22.

73. Vats, P., U. C. Banerjee. 2004. Production studies and catalytic properties of phytases (myo-inositol-hexakis-phosphate phosphohydrolases): an overview. Enzyme. Microb. Technol. 35:3-14

74. Viveros, A., A. Brenes, I. Arija, and C. Centeno. 2002. Effects of microbial phytase supplementation on mineral utilization and serum enzyme activities in broiler chicks fed different levels of phosphorus. Poult. Sci. 81:1172-1183.

75. Wealleans, A. L., L. P. Barnard, L. F. Romero, and C. Kwakernaak. 2016. A value based approach to determine optimal phytase dose: a case study in turkey poults. Anim. Feed. Sci. Tech. 216:288-295. 


\section{CHAPTER 2}

The effect of a dacitic (rhyolitic) tuff breccia (Azomite ${ }^{\circledR}$ ) in corn, soybean, and DDGS based diets that vary in inorganic phosphate source on pellet mill energy use, 0 to 21-day broiler performance, and apparent ileal amino acid digestibility.

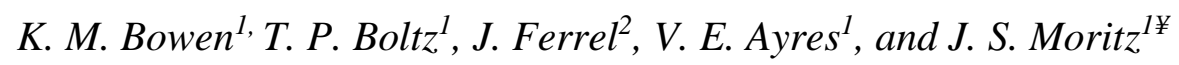

${ }^{1}$ Division of Animal and Nutritional Science, West Virginia University, Morgantown, West

Virginia, 26506

${ }^{2}$ Azomite Mineral Products, Nephi, Utah, 84648

$¥$ Corresponding Author: Joe.Moritz@mail.wvu.edu

Primary Audience: Feed Manufactures, Researchers, Nutritionists 


\section{SUMMARY}

Past research has shown that Azomite (AZM) can increase pellet mill production rate in diets that include inorganic phosphate sources (IPS) of dicalcium phosphate (DCP) or tricalcium phosphate (TCP). The authors hypothesized that if production rate were held constant then pellet mill energy consumption would decrease for diets that contained AZM due in part to a lubricating and/or pellet die scouring effect. This could decrease dietary amino acid exposure to frictional heat and pressure within the pellet die, maintaining amino acid conformation, and amino acid digestibility. The objective was to determine the effect of AZM (0.25\%) in diets with DCP and TCP on pellet mill energy consumption, subsequent live bird performance, and apparent ileal amino acid digestibility (AIAAD) when fed to broiler chicks for 21 days. Feed was manufactured in a 2 (IPS) x 2 (AZM inclusion) factorial across 4 days in a Latin square design. Post manufacture, three hundred twentyday-old Hubbard $\times$ Ross 708 males $(0.038 \mathrm{~kg} \pm 0.0014 \mathrm{SD})$ were allocated by weight to 8 replicates per treatment, 10 chicks per raised wire cage, in a randomized complete block design. Dietary treatments were arranged in a $2 \times 2$ factorial: DCP without AZM, TCP without AZM, DCP with AZM, and TCP with AZM. On d21 ileal contents were collected for amino acid and titanium dioxide analysis. Statistical analysis (Glimmix, SAS 9.4) was performed on the factorial arrangement of treatments and multiple comparisons were made of all treatments with post-hoc by Tukey's. Pellet mill motor load decreased by $5 \%$ in diets containing TCP compared to DCP $(P<0.001)$, and $1 \%$ when AZM was included $(P<0.001)$. An IPS $\times$ AZM inclusion interaction occurred for pellet durability $(P<0.001)$ and hot pellet temperature $(P<0.05)$. Pellet durability was increased in diets containing DCP when AZM was included, while TCP were unaffected. Hot pellet temperature increased for TCP diets with AZM, whereas DCP diets did not change. Apparent ileal digestibility of lysine, cysteine, and isoleucine were affected by the interaction of IPS and AZM inclusion $(P<0.05)$, demonstrating that processing with AZM increased digestibility 
in DCP diets but not TCP diets. Despite increased amino acid digestibility, AZM in DCP diets increased feed conversion ratio (FCR) by 0.02 (1.284 vs $1.303, P<0.05)$. However, AZM did not affect FCR in TCP diets (1.294 vs 1.285, $P>0.05$ ). Decreased pellet mill motor load that resulted from AZM inclusion suggests that feed was subjected to less frictional heat and/or pressure within the pellet die. This reduction in frictional heat and pressure likely preserved amino acid conformation, but the improvement was not translated to growth efficiency.

Key words: feed manufacture, tuff breccia, production rate, DDGS, broiler, amino acid digestibility

\section{DESCRIPTION OF PROBLEM}

Feed manufacture is a significant cost in meat-type poultry production (Cutlip et al., 2008). Due to expansion of poultry farms within integrated systems and greater feed volume requirements, milling equipment may be utilized beyond rated capacity more often than in the past. High pellet mill production rates typically decrease pellet quality due to decreased resident time of conditioned feed in the pellet die (Massuquetto et al., 2018; Briggs et al., 1999). Decreased exposure time of conditioned feed to increased pressure and frictional heat can decrease starch gelatinization, protein gelation, and ultimately pellet quality (Boroojeni et al., 2016; Abdollahi et al., 2013). These physical forces denature proteins prior to gelation. Protein denaturation exposes hydrophobic amino acids that are normally oriented inward, which lowers the solubility of the protein and thus reduces protein digestibility in the intestines (Boroojeni et al., 2016). According to Boroojeni et al. (2016) denaturation of proteins is dependent on four key factors; the type of 
protein involved, moisture content, pressure exerted on the protein, and salt concentration in the diet.

Use of inorganic phosphate sources (IPS) in commercial poultry feed has declined in recent years. This decline has been associated with expense, use of exogenous phytases, and decreased phosphorus safety margins for reduced environmental impact (Selle, 1997). Tricalcium phosphate (TCP) is an IPS known for having abrasive properties due to its angularity that can scour the inside of the pellet die and affect feed mill production rate, energy use of the pellet mill, or both (Behnke, 1981; Boltz et al., 2021). The pellet die scouring mechanism has been suggested to remove residual feed adhered to the inner die surface such as built-up gelatinized starch and gelled proteins (Behnke, 2007). Past literature has shown that corn, soybean meal, and dried distillers' grains with solubles (DDGS) based diets containing TCP can increase production rate $12 \%$ relative to diets containing dicalcium phosphate (DCP) (Boltz et al., 2021). In addition, TCP in corn and soybean meal-based diets have been shown to decrease pellet mill relative electrical energy usage by $11 \%$ when compared to DCP diets (Wamsley et al., 2012).

Decreased use of IPS leaves room in the diet formulation for nutritionists and manufactures to utilize novel pellet production aids. One product that has lubricating and die scouring potential is Azomite ${ }^{\circledR}(\mathbf{A Z M}$, Azomite Mineral Products, Nephi, UT). This product is of solidified volcanic igneous rock origination, comprised of a large portion of non-crystalline composite and characterized as a dacitic tuff breccia composition but is not strictly dacite. The two working hypotheses are 1) the hardness and irregular shape of AZM allows for pellet die scouring, and 2) AZM when exposed to steam generates additional lubrication from minor surface fractioning of mineral components.

Limited data exist on feeding AZM; however, results have suggested that AZM increases 
growth and efficiency. Tan et al. (2014) discovered that supplementing shrimp diets with $2.0 \mathrm{~g} \mathrm{~kg}^{-}$ ${ }^{1}$ AZM increased shrimp body weight (BW) by $13.98 \%$ and reduced feed conversion ratio (FCR) by 0.11 relative to the control group. The authors hypothesized that the rich hydrated aluminosilicate may remove toxins (Abbès et al., 2006) and that the rare earth elements may regulate intestinal microflora thus, improving nutrient digestion. Similarly, Liu et al. (2009) noted that tilapia decreased FCR and increased BW when supplemented with $0.25-0.75 \%$ AZM compared to the control group. A study performed by Pirzado et al. (2020) found that when broilers were fed a low energy diet supplemented with $0.25 \%$ AZM, birds had increased BW, average daily gain (ADG), and phosphorus and calcium digestibility with a decrease in FCR. Another study reported a decrease in FCR in post-molt hens when fed diets containing AZM (Malheiros et al., 2018). In agreement with the aforementioned researchers, Pirzado et al. (2021) observed a significant decrease in 42d FCR when birds were fed diets supplemented with $0.50 \%$ AZM relative to the control group. Juzaitis-Boelter et al. (2021) reported an increase in feed efficiency in broilers, total marketable eggs in laying hens, and total settable eggs in broiler breeder hens when supplemented with $0.125,0.250$, or $0.500 \%$ AZM. Further research into the effects of AZM on bird performance is needed.

Boltz et al. (2021) demonstrated that including AZM in DCP and TCP diets that were corn, soybean meal, and DDGS based increased feed production rate by 6 and 8\%, respectively. The authors hypothesized that diets with and without AZM pelleted at a constant production rate would express different degrees of frictional heat, pressure, and subsequent residence time within the pellet die. These differences may affect electrical energy use of the mill, pellet quality, and amino acid conformation. Tillman et al. (2020) found that the inclusion of AZM can increase production 
rate by $5.6 \%$ in diets containing DDGS, mono dicalcium phosphate, and meat and bone meal with no detriment to pellet quality.

The objective of the current study was to determine the effect of dacitic tuff breccia $\left(\right.$ Azomite $^{\circledR}$ ) inclusion in corn, soybean meal, and DDGS based diets that vary in rock phosphate source on electrical energy usage, pellet quality, d0-21 bird performance, and apparent ileal amino acid digestibility (AIAAD) when production rate was maintained constant.

\section{MATERIALS AND METHODS}

\section{Diet Formulation and Batching}

Corn and soybean meal-based starter diets with DDGS and a commercial phytase were formulated to $90 \%$ digestible amino acid requirements, similar to diets utilized by Bergeron et al. (2018) to test pelleting effects on nutrition (Table 1). Treatments were identical aside from phosphate source and inclusion or exclusion of AZM. Master batches of DCP and TCP formulations were batched and mixed without AZM or phytase. Master batches were weighed into 22.7 kilogram bags and allocated equally to treatment and day of manufacture in 454 kilograms experimental unit designations. AZM was substituted for corn when applicable and was mixed with phytase and approximately 3 kilograms of the appropriate master batch in a Univex paddle mixer for 5 minutes (Univex Floor Paddler Mixer, Model: M12B, Univex Corporation, Salem, $\mathrm{NH})$ prior to final mixing in a one-ton, vertical screw Easy Automation Inc. Modular Feed Processor (Easy Automation Inc., Welcome, MN). Each treatment replication received a 10 minute dry mix followed by an additional 10 minute post fat addition mix. Oil was added at a $1 \%$ inclusion rate at the mixer to mimic industry practice of adding a portion of oil/fat pre-pelleting. Treatments were crumbled and the remaining amount of oil was added back to the crumbles and mixed to achieve the formulated amount. 


\section{Feed Manufacture}

All feed was pelleted at the West Virginia University (WVU) pilot feed mill located in Morgantown, West Virginia during the month of July 2020 over a 4-day period. Days for pelleting were chosen based on warm ambient temperatures of $28^{\circ} \mathrm{C} \pm 2{ }^{\circ} \mathrm{C}$ to reduce variation during pelleting. Treatments were manufactured utilizing a 2 (AZM inclusion) $\times 2$ (phosphate source) factorial arrangement in a Latin Square Design, allowing for treatments to be manufactured in a different run order per replication day. A California Pellet Mill (CPM) conditioner, CPM hygieniser, 40 HP pellet mill (Master Model Pellet Mill, CPM, Crawfordsville, IN), and 4.8 x $38 \mathrm{~mm}$ CPM pellet die was utilized. Steam pressure measured at the gauge was adjusted to $276 \mathrm{kpa}$ (38 psi) prior to the Masoneilan Valve and entrance to the conditioner. For all treatments and days of manufacture, the feed auger rate from the surge bin to the conditioner was kept constant at $42 \%$. This feed auger rate produced pellet production above equipment rating in order to mimic industry practice. For this experiment, the hygieniser was not activated; therefore, no heated retention of feed occurred. However, feed still passed through the hygieniser, as there is no way to bypass the hygieniser within this feed manufacture system. After target temperature had been achieved for each treatment, pellet mill motor load was monitored using a Beta Raven programmable logic control system (PLC, 120V \#10113354; Beta Raven Automation Solutions, St. Charles, MO).

Beginning each replication day prior to manufacture of treatments, a high fiber ruminant diet was pelleted to warm the internal metal components of the WVU pelleting system. The high fiber in the formulation generated frictional heat in the pellet die without necessitating a high volume of warm-up feed. Post warming and based on the Latin Square Design, experimental mash treatments were conveyed to the surge bin above the pellet mill, where mash feed samples were obtained for nutrient analysis. The Masoneilan steam valve was opened gradually during start-up 
of pelleting until the goal conditioning temperature was achieved. All treatments were conditioned at $80^{\circ} \mathrm{C}$ for 30 seconds at a standardized $42 \%$ feed auger rate from the surge bin to the conditioner.

The authors attempted to eliminate confounding errors similar to the methodology of Boltz et al. (2021). The pellet mill was operated by the same person throughout the entirety of the study to mitigate operator error. Mixer added fat has die-lubricating properties that would increase production rate and confound the data; therefore, only $1 \%$ of the fat dictated by the diet formulation was added at the mixer. Each replication of the four dietary treatments was manufactured during warm ambient conditions that was more conducive to reducing errors related to greater steam volume required during cooler conditions. Utilizing the Latin square design reduces errors associated with fluctuating ambient temperature and humidity within and across each day of manufacture.

Five hundred grams of pelleted sample for nutrient analysis of each treatment replication was taken immediately after pellet die extrusion and placed on cheesecloth covering a large agricultural fan. This fan pulled ambient air across the pellets for a standardized time of 12 minutes to allow the pellets to cool and dry. This follows methodologies from Reese et al. (2017) that limit potential nutrient segregation effects of sampling post-pellet auguring. One kilogram of pelleted sample was collected from the cooler deck to determine pellet durability of each treatment replication. Throughout the manufacture of each treatment, extruded pellets were twice assayed for hot pellet temperature by using an insulated container to catch pellets, immediately closing the lid, and inserting an 80PK-24 temperature probe attached to a thermocouple (Fluke 51 II, Everette, WA). In addition, production rate was also measured twice by collecting extruded pellets for 60 seconds and weighing. Means of these repeated measures were used in the statistical analysis. Composite pelleted samples of each treatment intended for bird 
consumption were sent to a commercial laboratory to be analyzed for phytase activity (Eurofins Food and Feed Testing, Des Moines, IA). Five hundred grams of crumbled sample was also sent to a commercial laboratory for calcium, total phosphorus, phytic acid, and crude protein analysis for each treatment replication (NP Analytical Laboratories, St. Louis, MO; AOAC International, 2000; Method).

\section{Pellet Durability Analysis}

Pellet durability was determined on the day of manufacture utilizing a New Holmen Pellet Tester (New Holmen Pellet Durability Tester, Lignotech USA Inc., Rothschild, WI). Pelleted feed sample from each treatment replication was sifted using a No. 5 W.S. Tyler testing sieve (U.S.A Standard Test Sieve. No. 5. W.S. Tyler. Mentor, OH). One hundred grams of sifted pellets were placed in the New Holmen Pellet Tester perforated chamber, where forced air was applied for 30 seconds, and remaining pellets were weighed and recorded as a percentage. Pellet durability analyses were conducted in triplicate for each treatment, and results reflect average pellet durability.

\section{Particle Size}

Particle size of crumbled diets was measured using the WS Tyler Ro-Tap RX-29 Sieve Shaker where 100 gram of complete crumble samples were subjected to force through multiple sized enclosed sieves for 10 minutes (Table 3). Sieve sizes utilized, from the top of the machine to the bottom, were as follows: $4.75 \mathrm{~mm}, 3.35 \mathrm{~mm}, 2.36 \mathrm{~mm}, 1.7 \mathrm{~mm}, 1.18 \mathrm{~mm}, 850 \mu \mathrm{m}, 600 \mu \mathrm{m}$, $425 \mu \mathrm{m}, 300 \mu \mathrm{m}, 212 \mu \mathrm{m}, 150 \mu \mathrm{m}, 106 \mu \mathrm{m}$, and $75 \mu \mathrm{m}$. Mean geometric particle size and standard deviation were reported. 


\section{Live Bird Performance}

A total of 320 Hubbard $\times$ Ross 708 male one-day-old broiler chicks were obtained from a commercial hatchery (Longenecker's Hatchery, Elizabethtown, PA). On d1, the birds were weighed in groups of 10 , and allocated to 32 raised wire cages based on weight to create uniform initial pen weights. Treatments were allotted utilizing a randomized complete block design. Eight blocks were utilized that consisted of four adjacent cages per block. Treatments were randomly allocated to cages within each block. Feed and water were provided for ad libitum consumption via external troughs and nipple drinkers respectively. The study room was ventilated using negative pressure. Forced air heating and a mixer fan were also utilized as needed to maintain air flow and temperature uniformity throughout the entirety of the study. The birds were exposed to a decreasing lighting program throughout the duration of the study. Total hours of darkness per day were gradually increased until 6 hours per day was achieved similar to methodologies described by Lamp et al. (2015). Performance measurements taken included feed intake (FI), live weight gain (LWG) per bird, and mortality corrected FCR. On d21 birds were exposed to 6 hours dark, then 6 hours of light to encourage feed consumption to ensure that digesta would be present in the digestive tract for ileal collection and subsequent amino acid analysis. All animals were reared according to protocols approved by West Virginia University Animal Care and Use Committee.

\section{Ileum Digesta Collection and Apparent Ileal Amino Acid Digestibility}

On d21, all birds were euthanized via cervical dislocation. For digesta collection, the ileum was removed, from the Meckel's diverticulum to the ileo-cecal-colonic junction. This section was cut in half and collection was performed on the lower half nearest the ileo-cecal-colonic junction, similar to the procedure of Lamp et al. (2020). Contents were flushed using distilled water into clean, plastic containers. Digesta from 4 birds per pen were pooled, then freeze-dried at $-40^{\circ} \mathrm{C}$. Samples were then sent to a commercial laboratory for amino acid and $\mathrm{TiO}_{2}$ analysis (Experiment 
Station Chemical Laboratories, Columbia, MO). The percentage of AIAAD was determined using the following formula:

$\operatorname{AIAAD}(\%)=[1-(\mathrm{TDi} / \mathrm{TDO}) \times(\mathrm{No} / \mathrm{Ni})] \times 100$

where TDi represents the concentration of $\mathrm{TiO}_{2}$ in the diet in grams per kilogram of DM; TDO represents the concentration of $\mathrm{TiO}_{2}$ in the ileal digesta in grams per kilogram of DM output; $\mathrm{Ni}$ represents the concentration of nitrogen or AA in the diet in grams per kilogram DM; and No represents the concentration of nitrogen or AA in ileal digesta in grams per kilogram of DM.

\section{Statistical Analysis}

Variables were analyzed in a 2 (IPS) x 2 (AZM inclusion) factorial arrangement in a Latin Square Design across four manufacturing days with complete blocks in each day. The experimental unit consisted of one 454 kilogram batch of feed. Blocking criteria for feed manufacture was the day of manufacture and each treatment was manufactured at a different position in the pelleting order within day. The factorial arrangement was performed to compare main effect means and determine interactions between IPS and AZM. Data were analyzed in a mixed-model analysis using the GLIMMIX procedure of SAS (SAS Institute, Cary, NC 2017) with alpha set at $P \leq 0.05$ and a trend defined at $P \leq 0.10$. Possible interactions were tested for the combination of IPS x AZM. Linear contrasts were examined for treatment comparisons of interest.

Broiler performance and AIAAD experiments were conducted utilizing a randomized complete block design with a 2 (IPS) $\times 2$ (AZM inclusion) factorial arrangement. A cage of 10 birds served as the experimental unit for all parameters. Data were analyzed using a one-way ANOVA within SAS 9.4. Fisher's LSD test was used to further explore means when the main effect interaction was significant. Alpha was set at $P \leq 0.05$ for significance and a trend defined at $P \leq 0.10$, and letter superscripts were used to denote differences among treatment means. 


\section{RESULTS AND DISCUSSION}

\section{Feed Manufacture}

Feed manufacture data are presented in Table 4. TCP diets compared to DCP diets increased production rate by $2 \%(P=0.039)$, regardless of the experimental design that utilized a constant feeder rate into the pellet system. The increase in production rate has been observed in past research utilizing TCP diets. In addition, pellet mill motor load $(P<0.001)$ decreased $5 \%$ for TCP diets compared to DCP diets. TCP has been documented to have a pellet die scouring ability that removes residual feed that has adhered to the inner surface of the pellet die, allowing for enhanced production rate (Verner, 1988; Dietz, 1989; Wamsley et al., 2012; Boltz et al., 2021). The decrease that was observed for pellet mill motor load is likely also associated with the scouring ability of TCP. Removal of residual feed inside the pellet die may allow conditioned mash to flow through the die with low resistance resulting in lowered pellet mill motor load. The lower motor load indicates a potential decrease in total pressure exerted on the feed, while increased production rate may indicate a decrease in exposure time of pellets to pressure. Wamsley et al. (2012) found an $11 \%$ decrease in pellet mill energy usage for TCP diets relative to diets containing monocalcium phosphate sourced from two different manufacturing plants and DCP.

Pellet mill motor load was decreased by $1 \%$ with the inclusion of AZM $(P<0.001)$. The decrease in pellet mill motor load may be due to additional lubrication from minor surface fraction coating. In the current study, the ambient temperature averaged $28^{\circ} \mathrm{C}$ and mash temperature prior to conditioning in the surge bin averaged $33^{\circ} \mathrm{C}$. Past literature demonstrated that one percentage point of moisture is added for every $14^{\circ} \mathrm{C}$ increase in temperature during mash conditioning (Anon, 1984). To reach the goal conditioning temperature of $80^{\circ} \mathrm{C}$, the mash in the surge bin would have an approximate moisture addition of $3 \%$ that could have contributed to a minor surface fraction 
coating. Moore and Lockner (2004) found that addition of moisture to sheet structure minerals has been shown to decrease the friction between the minerals in the sheet structures. The AZM particles in the feed may utilize this property to decrease friction between the feed and pellet die, contributing to decreasing pellet mill motor load. It may be that the lubrication property of AZM coated the inside of the pellet die, allowing feed to flow more easily while generating less frictional heat. In addition, the pellet die scouring potential of AZM may have removed adhered gelled proteins and gelatinized starch from the inner surfaces of the pellet die, decreasing the electrical energy input required from the pellet mill. Boltz et al. (2020) demonstrated the angularity of AZM through scanning electron micrographs (Figure 1).

TCP diets with AZM tended to decrease pellet mill motor load $(P=0.070)$ compared to DCP diets with AZM. It is likely that the TCP and AZM combination provided more die scouring ability and lubrication resulting in improved milling efficiency at the pellet die.

TCP diets without AZM decreased pellet mill motor load compared to DCP diets without AZM by $4 \%(P=0.042)$. The observed decrease was likely associated with the increased scouring ability of TCP. Tricalcium phosphate diets without AZM tended to increase production rate $(P=0.083)$ by $1 \%$ compared to DCP diets with AZM.

An IPS $\times$ AZM inclusion interaction occurred for pellet quality $(P<0.001)$. Pellet quality increased for DCP diets when AZM was included, while AZM inclusion did not affect TCP diets. Linear contrasts among treatments of interest demonstrated that TCP diets with AZM decreased pellet durability relative to DCP diets with AZM by $8 \%(P=0.009)$. Dicalcium phosphate diets with AZM tended to increase pellet durability by $14 \%(P=0.066)$ compared to TCP diets without AZM. The scouring ability of TCP and subsequent increase in production rate decreased retention 
time, friction, and pressure of feed in the pellet die perhaps causing pellet durability to decrease (Dietz, 1989; Axe, 1996; Wasmsley et al., 2012; Boltz et al., 2021).

An IPS $\times$ AZM inclusion interaction occurred for hot pellet temperature $(P=0.019)$. Hot pellet temperature increased with the addition of AZM to TCP diets, while DCP diets were unaffected. The increase in production rate observed in TCP diets without AZM may have generated more friction between the inner surface of the pellet die and feed particles residing on the outer surface of the pellet that comes into direct contact with the die, thus increasing pellet temperature. The increase in temperature observed in diets containing TCP with AZM may be due to the decrease in motor load translating to a decrease in pressure exerted on the feed at the pellet die. However, the magnitude of change in hot pellet temperature is likely too small to be of practical significance on amino acid conformity and integrity.

\section{Apparent Ileal Amino Acid Digestibility}

The AIAAD data are presented in Table 5. Analysis of digesta and feed samples showed an IPS $\times$ AZM inclusion interaction for the ileal digestibility of lysine, isoleucine, and cysteine (lysine $P=0.039$; isoleucine $P=0.042$; cysteine $P=0.019$ ). The ileal digestibility of these amino acids increased in diets containing DCP with AZM inclusion relative to diets containing DCP without AZM. A possible explanation may be the decrease in motor load, and thus pressure exerted on the feed within the pellet die, decreased conformational changes in protein and amino acid, maintaining digestibility (Boroojeni et al., 2016). This may be due to the scouring capability and lubricating properties of AZM alleviating pressure. High temperatures have also been shown to deactivate amino acids, most notably heat labile amino acids such as lysine and cysteine (Boroojeni et al., 2016). The lubricating and scouring properties of AZM may have maintained the digestibility of amino acids by reducing the amount of surface area of the pellet that was exposed 
to frictional heat, confining it to the feed particles on the surface of the pellet in direct contact with the pellet die. The decreased exposure to heat may have maintained lysine conformation and ultimately digestibility by reducing or eliminating the occurrence of the Maillard browning reaction. The Maillard browning reaction favors high temperature and low moisture conditions (Marsman et al., 1995). Cheftel (1986) notes that moisture above 15\% during high temperature short time extrusion-cooking can help reduce loss of lysine. González-Vega et al. (2011) reported that autoclaving soybean meal at $125^{\circ} \mathrm{C}$ linearly decreased ileal digestibility of amino acids as the exposure time increased from 0 to 30 minutes due to the Maillard reaction. It may also be possible that AZM aided by interacting as an in-feed effect with various undefined toxins which led to a derived regulation of intestinal microflora as described by Tan et al. (2013), thus improving the digestibility of lysine, isoleucine, and cysteine. In addition, Lumpkins et al. (2014) found an increase in the duodenal villi height of broilers at inclusion rates of 0.25 or $0.50 \%$ AZM, that may increase the potential for nutrient digestion. Amino acid digestibility in TCP diets was unaffected by AZM inclusion. This could be due to the potential die scouring abilities of TCP already reducing pressure exerted on the feed and total feed exposure to heat.

Digestibility of glutamic acid, cysteine, and lysine significantly increased in TCP diets without AZM relative to DCP diets without AZM (glutamic acid $P=0.042$; cysteine $P=0.042$; $P=0.041)$. The digestibility of aspartic acid, glycine, and methionine tended to increase in TCP diets without AZM relative to DCP diets without AZM (aspartic acid $P=0.055$; glycine $P=0.084$; methionine $P=0.074)$.

\section{Bird Performance}

Bird performance data are presented in Table 6. No significant change was observed in 021d FI or LWG per bird in response to phosphate source or the inclusion of AZM. Inclusion of 
AZM increased FCR by 0.02 in birds fed diets containing DCP $(P=0.002)$ relative to those fed diets containing DCP without AZM. These data do not support the increase in AIAAD for DCP diets that contained AZM. Perhaps a longer-grow out period would better correlate AIAAD and bird performance. Loar et al. (2014) found an increase in amino acid digestibility and a decrease in FCR of 42d broilers; however, no significant change in FCR was observed on d21.

Analysis of phytase demonstrated that activity level dropped by approximately $60 \%$ from the formulated values across all four treatments (Table 1), (Eurofins Scientific, Des Moines, IA). This suggests that the phytase product may not have been able to withstand the conditioning temperatures or frictional forces of this particular feed manufacture process. However, 21d bird weights were consistent with Ross guidelines and the authors do not believe that a deficiency of phosphorus contributed to performance effects.

Results of this study suggest that through the use of AZM, feed mill operators can produce feed more economically by decreasing pellet mill motor load, while simultaneously reducing dependence on costly inorganic phosphates, with potential benefits on AIAAD.

\section{CONCLUSIONS AND APPLICATIONS}

1. Pellet mill motor load decreased by $5 \%$ in diets containing TCP compared to DCP, likely due to the more angular shape of TCP, allowing for souring of the pellet die.

2. Including AZM in diets at a $0.25 \%$ inclusion rate decreased pellet mill motor load by $1 \%$ in diets containing DCP or TCP.

3. AZM improved AIAAD in diets containing DCP likely by exposing feed to less pressure within the pellet die, and maintaining amino acid conformation, but the improvement was not translated to growth efficiency. Future research is needed to explore the effect of AZM on AIAAD and bird performance with a longer grow-out. 


\section{REFERENCES AND NOTES}

1. Abbès, S., Z. Ouanes, J. ben Salah-Abbès, Z. Houas, R. Oueslati. H. Bacha, and O. Othman. 2006. The protective effect of hydrated sodium calcium aluminosilicate against haematological, biochemical and pathological changes induced by Zearalenone in mice. Toxicon, 47:567-574.

2. Abdollahi, M. R., V. Ravindran, and B. Svihus. 2013. Pelleting of broiler diets: An overview with emphasis on pellet quality and nutritional value. Anim. Feed. Sci.

3. Axe, D. A. 1996. Effect of feed phosphates on the pelleting process: Research study at Kansas State University. IMC-Agrico Feed Ingredients, Bannockburn, Illinois, USA.

4. Azomite, Azomite Mineral Products, Nephi, Utah, USA.

5. Behnke, K. 2007. Feed manufacturing considerations for using DDGS in poultry and livestock diets. Proceedings. of the 5th Mid-Atl. Nutr. Conf. pp. 77-81.

6. Behnke, K. C. 1981. Pellet mill performance as affected by mineral source. Feedstuffs 53:34-36.

7. Bergeron, A. N., J. W. Boney, and J. S. Moritz. 2018. The effects of diet formulation and thermal processes associated with pelleting on 18-day broiler performance and digestible amino acid concentration. J. Appl. Poult. Res. 27:540-549.

8. Beta Raven Automation Solutions, St. Charles, MO.

9. Boltz, T. P., J. Ferrel, K. M. Bowen, K. L. Harding, V. E. Ayres, and J. S. Moritz. 2021. The effect of a dacitic tuff breccia (Azomite $\left.{ }^{\circledR}\right)$ in corn, soybean, and DDGS based diets that vary in inorganic phosphate source on pellet mill production rate and pellet quality. $\mathrm{J}$. Appl. Poult. Res. 30:100147

10. Boroojeni, F. G., B. Svihus, H. G. von Reichenbach, and J. Zentek. 2016. The effects of hydrothermal processing on feed hygiene, nutrient availability, intestinal microbiota and morphology in poultry-A review. Anim Feed. Sci. Tech. 220:187-215

11. Briggs, J. L., D. E. Maier, B. A. Watkins, and K. C. Behnke. 1999. Effect of ingredients and processing parameters on pellet quality. Poult. Sci. 78:1464-1471.

12. Cheftel, J. C. 1986. Nutritional effects of extrusion-cooking. Food. chem. 20:263-283.

13. Cutlip, S. E., J. M. Hott, N. P. Buchanan, A. L. Rack, J. D. Latshaw, and J. S. Moritz. 2008. The effect of steam-conditioning practices on pellet quality and growing broiler nutritional value. J. Appl. Poult. Res. 17:249-261.

14. Dietz, J. 1989. Effect of feed phosphates on the pelleting process: Research studies at Kansas State University. Pitman-Moore, Inc., Mundelein, Illinois, USA.

15. Europhins Food and Feed Testing, Des Moines, Iowa.

16. Experiment Station Chemical Laboratories, Agricultural Experiment Station, University of Missouri, Columbia.

17. Fluke 51 II, Everette, WA.

18. González-Vega, J. C., B. G. Kim, J. K. Htoo, A. Lemme, and H. H. Stein. 2011. Amino acid digestibility in heated soybean meal fed to growing pigs. J Anim Sci. 89:3617-3625.

19. Juzaitis-Boelter, C. P., A.P. Benson, M. U. Ahammad, M. K. Jones, J. Ferrel, and A. J. Davis. 2021. Dietary inclusion of AZOMITE improves feed efficiency in broilers and egg production in laying and broiler breeder hens. Poult. Sci. 100:101144. 
20. Lamp, A. E., A. M. Evans, and J. S. Moritz. 2015. The effects of pelleting and glucanase supplementation in hulled barley based diets on feed manufacture, broiler performance, and digesta viscosity. J. Appl. Poult. Res. 24: 295-303

21. Lamp, A. E., A. Mereu, I. Ruiz-Ascacibar, and J. S. Moritz. 2020. Inorganic feed phosphate type determines mineral digestibility, broiler performance, and bone mineralization.

22. Liu, A., X. Leng, X. Li, L. Wang, Y. Luo, and R. Zhu. 2009. Effects of azomite on growth, intestinal structure and non-specific immunity of tilapia (Oreochromis niloticus $X$ O. aureus). Chinese Journal of Animal Nutrition. 21:1006-1011.

23. Loar II, R. E., K. G. S. Wamsley, A. Evans, J. S. Moritz, and A. Corzo. 2014. Effects of varying conditioning temperature and mixer-added fat on feed manufacturing efficiency, 28-to 42-day broiler performance, early skeletal effect, and true amino acid digestibility. J. Appl. Poult. Res. 23:444-455.

24. Longnecker's Hatchery

25. Lumpkin, B., M. Greg, and J. Roger. 2014. The evaluation of natural mineral product (Azomite) when fed to broilers. Available at: http://azomiteinternational.com

26. Malheiros, R., V. Moraes, and K. Anderson. 2018. Effect of AZOMITE supplementation in post-molt hens. Poult. Sci. 107(E-Suppl. 1):161.

27. Marsman, G. J. P., H. Gruppen, A. F. B. Van der Poel, J. W. Resink, M. W. A. Verstegen, and A. G. J. Voragen. 1995. The effect of shear forces and addition of a mixture of a protease and a hemicellulase on chemical, physical and physiological parameters during extrusion of soybean meal. Anim. Feed. Sci. Tech. 56:21-35.

28. Massuquetto, A., J. F. Durau, V. G. Schramm, M. T. Netto, E. L. Krabbe, and A. Maiorka. 2018. Influence of feed form and conditioning time on pellet quality, performance and ileal nutrient digestibility in broilers. J. Appl. Poult. Res. 27:51-58.

29. Master Model Pellet Mill, California Pellet Mill Company, Crawfordsville, IN.

30. Moore, D. E. and D.A. Lockner. 2004. Crystallographic controls on the frictional behavior of dry and water-saturated sheet structure minerals. J. Geophys. Res. 109: B03401.

31. New Holmen Portable Pellet Durability Tester, Lignotech USA Inc., Rothschild, WI.

32. NP Analytical Laboratories, St. Louis, MO

33. One-ton vertical screw Easy Automation Inc. Modular Feed mixer, Easy Automation Inc., Welcome, MN.

34. Pirzado, S. A., A. Purba, C. Huiyi, C. Guilin, and L. Gouhua. 2020. Effect of azomite with low energy diet on growth performance, nutrient digestibility and bone mineralization of broiler chickens. Intl. J. Agric. Biol. 24:505-510.

35. Pirzado, S. A., W. Zhengke, C. J. Adanan Purba, H. Cai, C. Guilan, and G. Liu. 2021. Effect of Azomite on Growth Performance, Nutrient Retention, Immunity and Bone Mineralization of Broiler Chickens.

36. Reese, D. A., K. L. Foltz, and J. S. Moritz. 2017. Effect of mixing and sampling method on pelleted feed nutrient analysis and diet formulation validation. J. Appl. Poult. Res. 26:219-225.

37. SAS Institute. 2017. The SAS System for Windows 2017. Release 9.4 SAS Inst. Inc., Cary, NC. 
38. Selle, P. H. 1997. The potential of microbial phytase for the sustainable production of pigs and poultry: an Australian perspective. Korean J anim Nutr Feedstuffs. Seventh Short Course on Feed Technology, 3:1-39.

39. Tan, C. G., X. Q. Li, X. J. Leng, X. G. Su, L. Chen, B. Liu, F. Ma, X. Q. Cai, and T. Guo. 2014. Effects of supplemental Azomite in diets on growth, immune function and disease resistance of white shrimp (L itopenaeus vannamei). Aquaculture Nutrition. 20:324-331.

40. Tillman, N. S., M. K. Jones, and W. J. Pacheco. 2020. Influence of feed ingredients, conditioning temperature, and AZOMITE on pellet production rate and pellet quality. J. Appl. Poult. Res. https://doi.org/10.1016/j.japr.2019.10.003.

41. U.S.A Standard Test Sieve. No. 6. W.S. Tyler. Mentor, OH.

42. Univex Floor Paddler Mixer, Univex Corporation, Salem, NH.

43. Verner, W. A. 1988. Phosphates in pelleting: Best cost vs. least cost. Feed Management 39(4):56-58.

44. Wamsley, K. G. S., C. K. Gehring, A. Corzo, E. A. Fontana, and J. S. Moritz. 2012. Effects of inorganic feed phosphate on feed quality and manufacturing efficiency. J. Appl. Poult. Res. 21:823-829. 
Table 1. Broiler finisher formulations for diets containing dicalcium phosphate (DCP) or tricalcium phosphate (TCP) (\% diet).

\begin{tabular}{|c|c|c|c|c|}
\hline Ingredients & \multicolumn{2}{|c|}{ DCP } & \multicolumn{2}{|c|}{ TCP } \\
\hline Corn & \multicolumn{2}{|c|}{58.28} & \multicolumn{2}{|c|}{58.99} \\
\hline Soybean Meal (45\%) & \multicolumn{2}{|c|}{30.78} & \multicolumn{2}{|c|}{30.72} \\
\hline Corn DDGS & \multicolumn{2}{|c|}{5.00} & \multicolumn{2}{|c|}{5.00} \\
\hline Soy oil - only $1 \%$ added at the mixer & \multicolumn{2}{|c|}{1.70} & \multicolumn{2}{|c|}{1.46} \\
\hline Dicalcium P or Tricalcium P & \multicolumn{2}{|c|}{1.61} & \multicolumn{2}{|c|}{1.66} \\
\hline Limestone & \multicolumn{2}{|c|}{1.17} & \multicolumn{2}{|c|}{0.91} \\
\hline Salt & \multicolumn{2}{|c|}{0.27} & \multicolumn{2}{|c|}{0.07} \\
\hline DL - Methionine & \multicolumn{2}{|c|}{0.42} & \multirow{2}{*}{\multicolumn{2}{|c|}{0.42}} \\
\hline Vitamin/Mineral Premix ${ }^{1}$ & \multicolumn{2}{|c|}{0.25} & & \\
\hline L-Lysine - $\mathrm{HCl}$ & \multicolumn{2}{|c|}{0.16} & \multicolumn{2}{|c|}{0.16} \\
\hline L-Threonine & \multicolumn{2}{|c|}{$\begin{array}{l}0.26 \\
0.10\end{array}$} & \multicolumn{2}{|c|}{0.26} \\
\hline Sodium Bicarbonate & & & \multicolumn{2}{|c|}{0.10} \\
\hline Azomite substituted for corn when applicable & \multicolumn{2}{|c|}{0.25} & \multicolumn{2}{|c|}{0.25} \\
\hline Phytase $^{2}$ & \multicolumn{2}{|c|}{0.02} & \multicolumn{2}{|c|}{0.02} \\
\hline \multicolumn{5}{|l|}{ Calculated Nutrient Values ${ }^{3}(\%)$} \\
\hline ME (kcal/lbs) & & & & \\
\hline Crude Protein & & & & \\
\hline Dig Lysine & & & & \\
\hline Dig TSAA & & & & \\
\hline Dig Methionine & & & & \\
\hline Dig Threonine & & & & \\
\hline Dig Tryptophan & & & & \\
\hline Calcium & & & & \\
\hline Non-phytate Phosphorus ${ }^{4}$ & & & & \\
\hline Sodium & & & & \\
\hline & & nalyze & lues $(\%)$ & \\
\hline & & & & \\
\hline & Control & AZM & Control & AZM \\
\hline Crude Protein ${ }^{5}$ & 21.2 & 21.5 & 21.3 & 21.3 \\
\hline Calcium $^{6}$ & 1.20 & 1.15 & 0.99 & 1.07 \\
\hline Total Phosphorus ${ }^{7}$ & 0.70 & 0.71 & 0.63 & 0.67 \\
\hline Phytic Acid Ion Exchange ${ }^{8}$ & 0.80 & 0.85 & 0.86 & 0.86 \\
\hline Non-phytate Phosphorus ${ }^{9}$ & 0.47 & 0.47 & 0.39 & 0.43 \\
\hline Phytase $(\mathrm{FTU} / \mathrm{kg})^{10}$ & 470 & 420 & 390 & 430 \\
\hline
\end{tabular}

Digestible amino acids were based on the digestible lysine value (1.2\%) suggested by P. B. Tillman and W.A. Dozier. 2013. Current Amino Acid Considerations for Broilers: Requirements, Ratios, Economics. www.thepoultryfederation.com for 8 14 day broilers. Digestible amino acid to digestible lysine ratios followed further minimum recommendations of this communication ( 0.54 methionine, 0.90 TSAA, 0.84 threonine, 0.19 tryptophan).

${ }^{1}$ Supplied the following per kilogram of diet: manganese, $0.02 \%$; zinc, $0.02 \%$; iron, $0.01 \%$; copper, $0.0025 \%$; iodine, $0.0003 \%$; selenium, $0.00003 \%$; folic acid, $0.69 \mathrm{mg}$; choline, $386 \mathrm{mg}$; riboflavin, $6.61 \mathrm{mg}$; biotin, $0.03 \mathrm{mg}$; vitamin B6, $1.38 \mathrm{mg}$; niacin, $27.56 \mathrm{mg}$; pantothenic acid, $6.61 \mathrm{mg}$; thiamine, $2.20 \mathrm{mg}$; menadione, $0.83 \mathrm{mg}$; vitamin B12, $0.01 \mathrm{mg}$; vitamin E, $16.53 \mathrm{IU}$; vitamin D3, 2,133 ICU; vitamin A, 7,716 IU.

${ }^{2}$ Phytase was top dressed at 1,000 FTU/kg - Quantum Blue, AB Vista.

${ }^{3}$ Metabolizable Energy and Available Phosphorus were based on Agristat values as suggested by M. Donohue. 2013.

The Challenges in Feeding Broilers in Times of High and Volatile Feed Ingredient Costs: How to Cover the Costs?

2013 Mid- Atlantic Nutrition Conference proceedings. A 2.2 ratio was maintained for Ca to AP.

${ }^{4}$ Non-Phytate Phosphorus (nPP) was calculated using the following equation: (Total Phosphorus - $(0.282 *$ Phytic Acid)).

${ }^{5}$ AOAC Method 988.05, 920.87, 991.20; Kjeldahl.

${ }^{6}$ AOAC Method 968.08, 927.02, 935.13, 985.35; Atomic Absorption Spectrophotometry.

${ }^{7}$ AOAC Method 965.17; Spectrophotometry.

${ }^{8}$ AOAC Method 986.11.

${ }^{9}$ Non-phytate phosphorus $=$ total phosphorus $($ AOAC Method 965.17) $-[0.282 \times$ phytic acid $] \times 100$.

${ }^{10}$ AOAC method 2000.12. 
Table 2. Feed particle size for feed manufactured at the WVU pilot mill in July, 2020. Feed was manufactured using a 40 horsepower California Pellet Mill and were extruded through a $4.8 \times 38 \mathrm{~mm}$ pellet die and then crumbled using a roller mill.

\begin{tabular}{|c|c|c|c|}
\hline Phosphate Source & $\begin{array}{c}\text { Azomite } \\
\text { Inclusion }\end{array}$ & Particle Size $(\mu \mathrm{m})$ & Standard Deviation $(\mu \mathrm{m})$ \\
\hline Dicalcium Phosphate & No Azomite & 1168.51 & 1.93 \\
\cline { 2 - 4 } & Azomite & 1066.22 & 1.98 \\
\hline Tricalcium Phosphate & No Azomite & 1135.02 & 1.94 \\
\cline { 2 - 4 } & Azomite & 1035.76 & 1.97 \\
\hline
\end{tabular}

${ }^{1} 0.7$ and $0.46 \%$ oil was blended post batching to the dicalcium phosphate and tricalcium phosphate treatments respectively prior to crumbling.

Table 3. Analyzed Nutrients for Phosphate Sources, Azomite Product, and DDGS.

\begin{tabular}{cccccc}
\hline Ingredient & $\begin{array}{c}\text { Total Calcium } \\
(\%)\end{array}$ & $\begin{array}{c}\text { Total } \\
\text { Phosphorus } \\
(\%)\end{array}$ & $\begin{array}{c}\text { Crude } \\
\text { Fiber }^{3} \\
(\%)\end{array}$ & $\begin{array}{c}\text { Crude } \\
\text { Fat }^{4} \\
(\%)\end{array}$ & $\begin{array}{c}\text { Crude }_{\text {Protein }^{5}} \\
(\%)\end{array}$ \\
\hline Dicalcium Phosphate & 17.6 & 15.20 & - & - & - \\
Tricalcium Phosphate & 31.0 & 18.1 & - & - & - \\
Azomite Product & 1.60 & 0.0258 & - & - & 27.04 \\
DDGS & 0.043 & 0.818 & 8.09 & 4.76 & 2 \\
\hline
\end{tabular}

${ }^{1}$ Total calcium was determined using atomic absorption spectroscopy.

${ }^{2}$ Total phosphorus was determined using colorimetric spectroscopy.

${ }^{3}$ Crude fiber was determined by extracting fiber residue to be weighed, then was ignited and reweighed to calculate the loss on ignition of residue.

${ }^{4}$ Crude fat was determined using petroleum ether in a soxhlet apparatus method.

${ }^{5}$ Crude protein was determine using the traditional kjeldahl method 
Table 4. The effects of phosphate source and Azomite inclusion on feed manufacture variables and pellet quality.

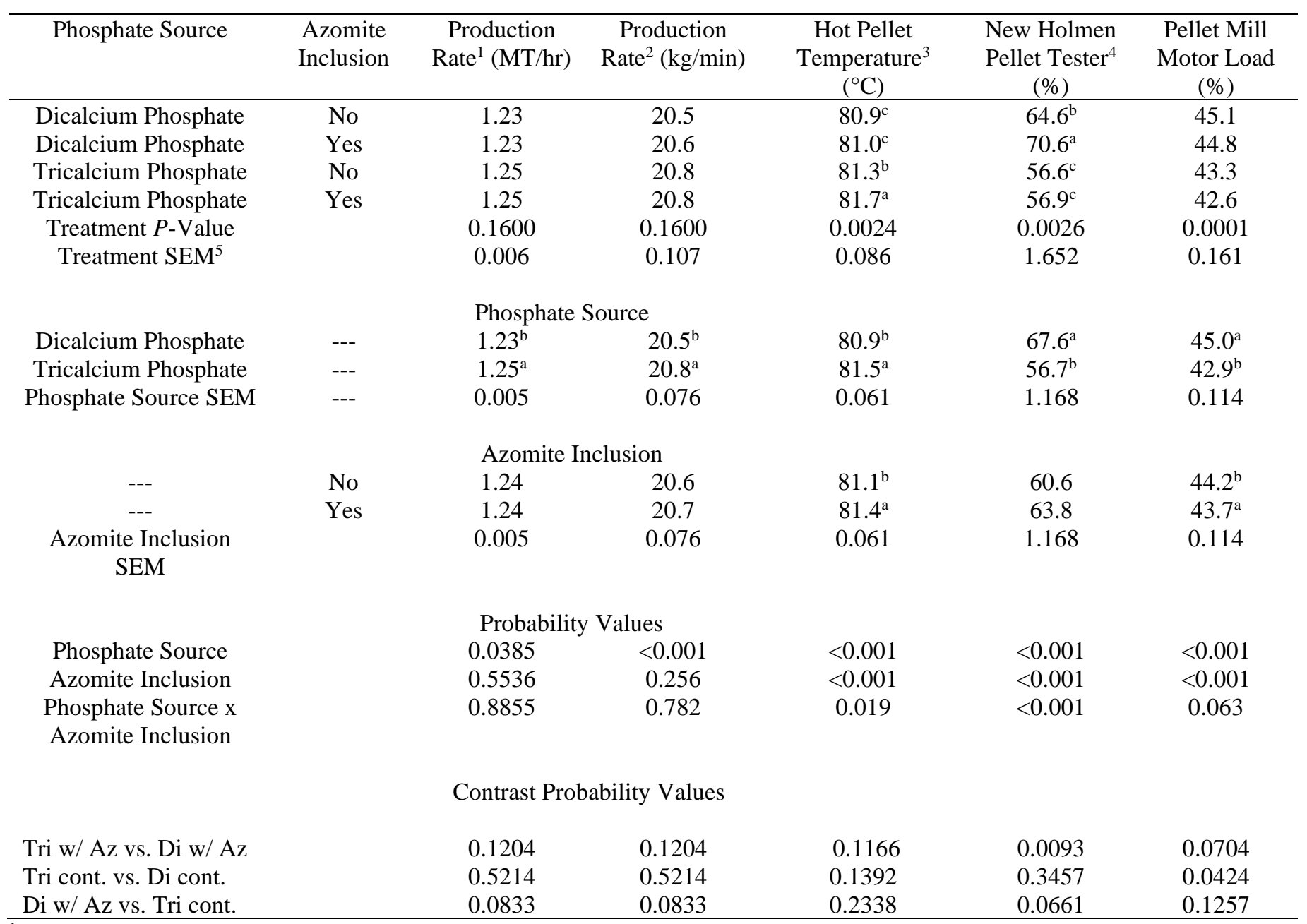

${ }^{1}$ Production rate $(\mathrm{MT} / \mathrm{hr})$ was calculated based on multiple measures of $\mathrm{kg} / \mathrm{min}$. Mean values represented each treatment replication.

${ }^{2}$ Production rate $(\mathrm{kg} / \mathrm{min})$ was measured. Multiple measures were obtained, and mean values represented each treatment replication.

${ }^{3}$ Hot pellet temperature was determined on multiple samples of pellets directly following extrusion from the die. Mean values represented each treatment replication. Pellets were collected into an insulated container and temperature was measured using a thermocouple thermometer and an 80PK-24 temperature probe.

${ }^{4}$ Durability was measured using the New Holmen Pellet Tester where 100 gram pelleted samples are subjected to air flow within a perforated chamber for 30 seconds. The assay was determined on the evening that each treatment was manufactured.

${ }^{5}$ SEM: Pooled Standard Error of the Mean.

${ }^{\mathrm{a}-\mathrm{b}}$ Means within a column not sharing a common superscript differ significantly $(\mathrm{P}<0.05)$ 
Table 5. Apparent Ileal Amino Acid Digestibility (AIAAD) of 21-day old broilers

\begin{tabular}{|c|c|c|c|c|c|c|c|c|c|c|c|c|c|}
\hline Phosphate Source & $\begin{array}{l}\text { Azomite } \\
\text { Inclusion }\end{array}$ & Asp & Thr & Glu & Pro & Gly & Ala & Cys & Val & Met & Ile & Leu & Lys \\
\hline DCP & No & 83.5 & 84.1 & $89.2^{\mathrm{b}}$ & 87.0 & 81.0 & 85.5 & $74.6^{\mathrm{b}}$ & 83.3 & 94.3 & 85.4 & 87.3 & $87.9^{\mathrm{b}}$ \\
\hline DCP & Yes & 84.7 & 85.9 & $90.3^{\mathrm{ab}}$ & 88.3 & 82.8 & 87.2 & $77.6^{\mathrm{a}}$ & 85.1 & 94.8 & 86.9 & 88.7 & $89.6^{\mathrm{a}}$ \\
\hline TCP & No & 85.0 & 85.4 & $90.9^{\mathrm{a}}$ & 87.9 & 82.8 & 86.9 & $77.9^{\mathrm{a}}$ & 84.8 & 95.3 & 87.0 & 88.4 & $90.0^{\mathrm{a}}$ \\
\hline TCP & Yes & 84.4 & 85.4 & $90.4^{\mathrm{ab}}$ & 87.6 & 82.1 & 86.6 & $76.7^{\mathrm{ab}}$ & 83.9 & 95.0 & 86.1 & 88.1 & $89.3^{\mathrm{ab}}$ \\
\hline Treatment $P$-Value & & 0.178 & 0.169 & 0.082 & 0.248 & 0.164 & 0.254 & 0.042 & 0.239 & 0.193 & 0.175 & 0.271 & 0.056 \\
\hline Treatment SEM ${ }^{1}$ & & 0.499 & 0.564 & 0.438 & 0.447 & 0.618 & 0.629 & 0.827 & 0.666 & 0.304 & 0.568 & 0.517 & 0.520 \\
\hline \multicolumn{14}{|c|}{ Phosphate Source } \\
\hline DCP & --- & 84.1 & 85.0 & 89.8 & 87.6 & 81.9 & 86.3 & 76.1 & 84.2 & 94.6 & 86.1 & 88.0 & 88.8 \\
\hline TCP & --- & 84.7 & 85.4 & 90.6 & 87.7 & 82.4 & 86.8 & 77.3 & 84.3 & 95.2 & 86.5 & 88.2 & 89.7 \\
\hline Phosphate Source SEM & --- & 0.353 & 0.399 & 0.310 & 0.316 & 0.437 & 0.445 & 0.585 & 0.471 & 0.215 & 0.402 & 0.365 & 0.368 \\
\hline \multicolumn{14}{|c|}{ Azomite Inclusion } \\
\hline--- & No & 84.2 & 84.7 & 90.1 & 87.4 & 81.9 & 86.2 & 76.3 & 84.1 & 94.8 & 86.2 & 87.8 & 88.9 \\
\hline--- & Yes & 84.6 & 85.6 & 90.4 & 87.9 & 82.4 & 86.9 & 77.2 & 84.5 & 94.9 & 86.5 & 88.4 & 89.5 \\
\hline Azomite Inclusion SEM & & 0.353 & 0.399 & 0.310 & 0.316 & 0.437 & 0.445 & 0.585 & 0.471 & 0.215 & 0.402 & 0.365 & 0.368 \\
\hline \multicolumn{14}{|c|}{ Probability Values } \\
\hline Phosphate Source & & 0.215 & 0.476 & 0.066 & 0.765 & 0.388 & 0.510 & 0.164 & 0.884 & 0.073 & 0.481 & 0.594 & 0.097 \\
\hline Azomite Inclusion & & 0.505 & 0.130 & 0.510 & 0.241 & 0.394 & 0.252 & 0.283 & 0.491 & 0.776 & 0.628 & 0.308 & 0.330 \\
\hline $\begin{array}{l}\text { Phosphate Source } \mathrm{x} \\
\text { Azomite Inclusion }\end{array}$ & & 0.083 & 0.126 & 0.076 & 0.103 & 0.056 & 0.126 & 0.019 & 0.057 & 0.232 & 0.042 & 0.109 & 0.039 \\
\hline \multicolumn{14}{|c|}{ Contrast Probability Values } \\
\hline Tri w/ Az vs. Di w/ Az & & 0.632 & 0.385 & 0.952 & 0.300 & 0.305 & 0.433 & 0.232 & 0.143 & 0.547 & 0.290 & 0.399 & 0.634 \\
\hline Tri cont. vs. Di cont. & & 0.055 & 0.202 & 0.042 & 0.210 & 0.084 & 0.156 & 0.042 & 0.171 & 0.106 & 0.074 & 0.159 & 0.041 \\
\hline Di w/ Az vs. Tri cont. & & 0.493 & 0.297 & 0.172 & 0.236 & 0.989 & 0.552 & 0.786 & 0.492 & 0.055 & 0.738 & 0.386 & 0.267 \\
\hline
\end{tabular}

DCP = Dicalcium Phosphate, TCP $=$ Tricalcium Phosphate

${ }^{1}$ Standard Error of the Mean

${ }^{\mathrm{a}-\mathrm{b}}$ Means within a column not sharing a common superscript differ significantly $(\mathrm{P}<0.05)$ 
Table 6. The effects of phosphate source and Azomite inclusion on live bird performance of Hubbard $\times$ Ross 708 broiler chicks.

\begin{tabular}{|c|c|c|c|c|c|}
\hline Phosphate Source & $\begin{array}{l}\text { Azomite } \\
\text { Inclusion }\end{array}$ & $\begin{array}{c}\text { Day } 0 \text { Pen } \\
\text { Weight }^{1}(\mathrm{~kg})\end{array}$ & $\begin{array}{c}\text { Day 0-21 FI } \\
\text { per Bird }{ }^{2} \\
(\mathrm{~kg})\end{array}$ & $\begin{array}{c}\text { Day 0-21 FCR } \\
\text { (kg/kg) }\end{array}$ & $\begin{array}{c}\text { Day 0-21 LWG } \\
\text { per Bird }{ }^{4}(\mathrm{~kg})\end{array}$ \\
\hline Dicalcium Phosphate & No & 0.378 & 1.207 & $1.284^{\mathrm{b}}$ & 0.940 \\
\hline Dicalcium Phosphate & Yes & 0.378 & 1.191 & $1.303^{\mathrm{a}}$ & 0.910 \\
\hline Tricalcium Phosphate & No & 0.377 & 1.195 & $1.294^{\mathrm{ab}}$ & 0.923 \\
\hline Tricalcium Phosphate & Yes & 0.378 & 1.196 & $1.285^{\mathrm{b}}$ & 0.915 \\
\hline Treatment $P$-Value & & 0.9091 & 0.9720 & 0.0083 & 0.6560 \\
\hline Treatment SEM ${ }^{5}$ & & 0.001 & 0.025 & 0.004 & 0.018 \\
\hline \multicolumn{6}{|c|}{ Phosphate Source } \\
\hline Dicalcium Phosphate & --- & 0.3780 & 1.1992 & 1.2933 & 0.9252 \\
\hline Tricalcium Phosphate & --- & 0.3776 & 1.1954 & 1.2896 & 0.9192 \\
\hline Phosphate Source SEM & --- & 0.010 & 0.018 & 0.003 & 0.0126 \\
\hline \multicolumn{6}{|c|}{ Azomite Inclusion } \\
\hline--- & No & 0.3776 & 1.2009 & 1.2888 & 0.9317 \\
\hline--- & Yes & 0.3780 & 1.1937 & 1.2941 & 0.9127 \\
\hline Azomite Inclusion SEM & & 0.001 & 0.018 & 0.003 & 0.013 \\
\hline \multicolumn{6}{|c|}{ Probability Values } \\
\hline Phosphate Source & & 0.7396 & 0.8816 & 0.3581 & 0.7387 \\
\hline Azomite Inclusion & & 0.7268 & 0.7751 & 0.1921 & 0.2957 \\
\hline Phosphate Source x Azomite & & 0.5900 & 0.7294 & 0.0019 & 0.5471 \\
\hline \multicolumn{6}{|c|}{ Contrast Probability Values } \\
\hline Tri w/ Az vs. Di w/ Az & & 0.8789 & 0.8520 & 0.0082 & 0.7950 \\
\hline Tri cont. vs. Di cont. & & 0.5738 & 0.4952 & 0.0131 & 0.2658 \\
\hline Di w/ Az vs. Tri cont. & & 0.7169 & 0.9418 & 0.2026 & 0.7270 \\
\hline
\end{tabular}


Figure 1. 50,000-scanning electron microscope of Azomite feed grit with an FEI.

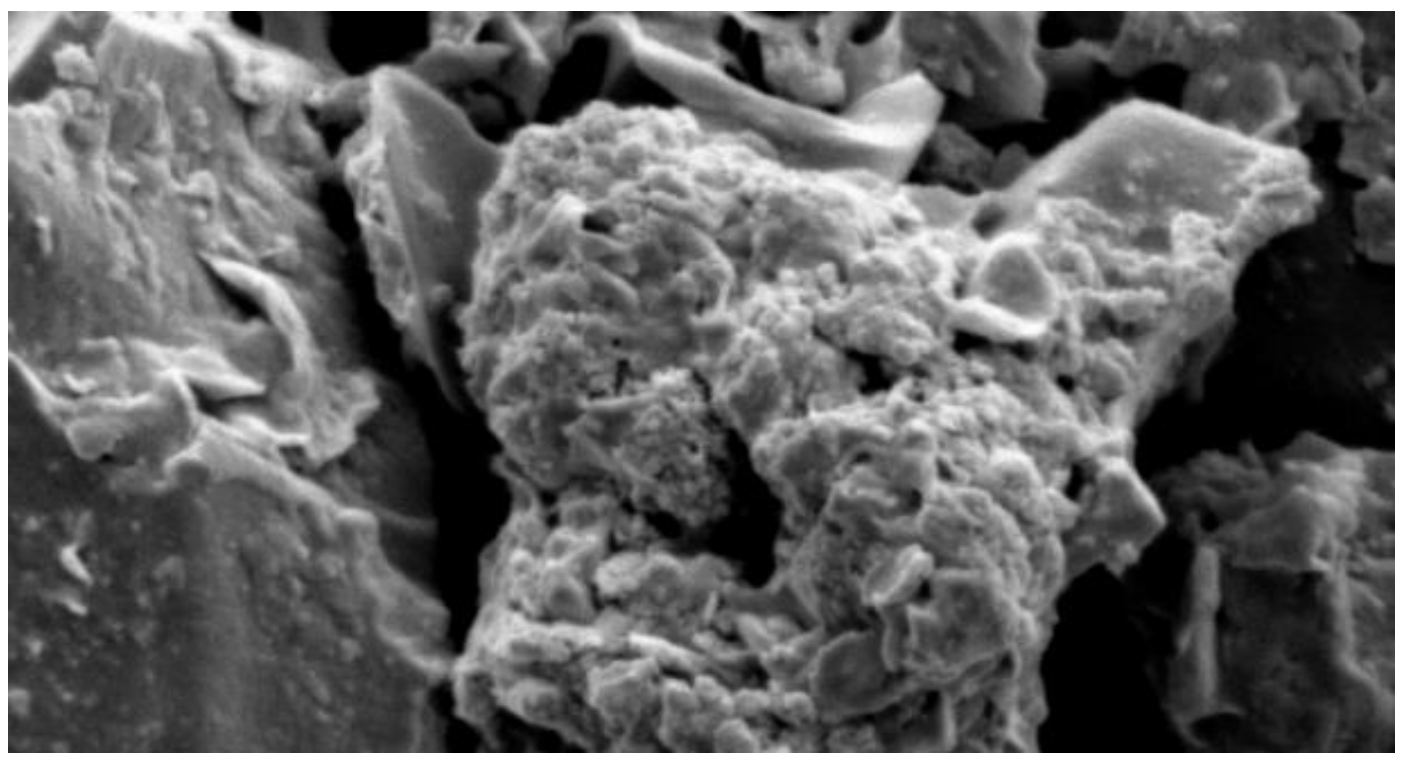




\section{CHAPTER 3}

Performance, carcass quality, tibia ash, and mineral digestibility responses of Ross 708 broilers to increasing dose of two commercially available mixer-added phytases.

K. M. Bowen ${ }^{1}$, M. Jackson ${ }^{2}$, V. E. Ayres ${ }^{1}$, T. P. Boltz ${ }^{1}$, E. A. Lynch ${ }^{1}$, and J. S. Moritz ${ }^{1 ¥}$

${ }^{1}$ Division of Animal and Nutritional Sciences, West Virginia University, Morgantown, West

Virginia, 26506

${ }^{2}$ Huvepharma

¥ Corresponding Author: Joe.Moritz@mail.wvu.edu

Primary Audience: Feed Manufactures, Researchers, Nutritionists 


\section{SUMMARY}

Mixer added phytases must retain efficacy post conditioning and pelleting. Heat from saturated steam and friction upon pellet die extrusion may deactivate phytases. In addition, increasing phytase concentrations in diets may increase nutrient release from phytate. The objective of this study was to assess two commercially available phytases that were concentrated at 500, 1,000 , or $2,000 \mathrm{FTU} / \mathrm{kg}$ in mixed mash post steam conditioning at $82^{\circ} \mathrm{C}$ for $30 \mathrm{sec}$ and extrusion through a $4.8 \times 38 \mathrm{~mm}$ pellet die on 0 to $44 \mathrm{~d}$ Ross 708 male broiler performance, mineral digestibility, and tibia ash responses. The phytase sources were both derived from E. coli and expressed in Trichoderma Reesei, (QB) and expressed in Pichia pastoris, (OP). A 3 (Phytase level) $\times 2$ (Phytase source) factorial arrangement of treatments within a randomized complete block design was utilized. A positive control and negative control diet based on available phosphorus $(\mathbf{P})$ and total calcium $(\mathbf{C a})$ were also manufactured and analyzed within a multiple comparison. Crumbled and pelleted diets were fed to 8 replicate pens of 30 chicks in three phases. Live performance, d20 and d44 tibia ash, d44 hot boneless, skinless breast weight and mineral digestibility were measured. Day 44 live weight gain (LWG) and both d20 and d44 tibia measures increased for all phytase concentrations relative to the negative control $(P<0.05)$. Phytase sources did not differ in their effect on live performance or breast yield with the exception of live weight at 20 days where birds provided with OP were heavier $(P<0.05)$. Calcium digestibility was increased for birds fed OP relative to QB $(P<0.05)$. Phosphorus digestibility increased when either source was fed and was higher with OP compared to QB at $500 \mathrm{FTU} / \mathrm{kg}(P<0.05)$. Day 20 tibia ash percentage increased for 1,000 and 2,000 FTU/kg concentrations for both phytase sources while mg tibia ash increased with all levels of both sources compared to the control $(P<0.05)$. Mg tibia ash was higher with OP compared to QB at the 500 FTU level $(P<0.05)$. Both phytase sources increased d44 percent and mg tibia ash relative to the negative control with OP exceeding QB at 1,000 and 2,000 FTU for tibia ash 
percent and at 2,000 FTU for mg tibia ash $(P<0.05)$. The assessed phytase sources showed similar benefit to live performance and breast yield but varied in response to tibia ash and mineral digestibility at different concentrations.

Keywords: Phytase, mixer added, tibia ash, live bird performance, thermostability

\section{DESCRIPTION OF PROBLEM}

Heat stability of phytase products is a main concern of feed manufacturers, notably when feed is further processed into pellets as is often the case for meat type poultry. Jongbloed and Kemme (1990) found that diets containing a high phytase activity of 1,174 FTU/kg from feedstuffs experienced a decrease in the phosphorus $(\mathbf{P})$ and calcium $(\mathbf{C a})$ absorbability by at least 10 percentage points when exposed to approximately $80^{\circ} \mathrm{C}$ during conditioning. The authors noted that the reduction in absorbability was mainly due to a reduction in phytase activity. Feed mills often operate at a conditioning temperature of 80 to $90^{\circ} \mathrm{C}$. Furthermore, higher temperatures of up to $200^{\circ} \mathrm{C}$ have been reported during the pellet extrusion process (Boroojeni et al., 2016). Many feed manufacturers apply phytase post pelleting to avoid heat deactivation of the enzyme. It should be noted, however, that there is often a loss of phytase activity associated with post pellet application if transported and/or stored for long periods of time, especially at high temperatures, likely because the phytase is exposed on the outside of the pellet (Slominski et al., 2007; De Bruyne, 2000). Another drawback to post pellet application is the additional costly equipment that is required (Slominski et al., 2007). It is also noteworthy to mention the decrease in pellet quality that may occur.

Granulated phytase products are available that possess a heat tolerant coating to prevent heat damage to the enzyme (Timmons et al., 2008). Thus, the enzyme should be 
thermostable at conventional conditioning temperatures of $80^{\circ} \mathrm{C}$ or greater during pelleting. The development of these heat stable phytase products has resulted in the addition of phytase at the mixer becoming a more common practice.

The findings of Wyss et al. (1998) suggest that the microorganism that the phytase is sourced from and its subsequent expression can impact the thermostability of the product and influence the enzyme's ability to refold once denatured. In the current study one of the phytase products, Optiphos Plus (OP), is a granular product with an activity level of 10,000 FTU/g. The other product to be compared is Quantum Blue $(\mathbf{Q B})$, and is a powdered product and has an activity level of 5,000 FTU/g. Both sources are described as intrinsically heat tolerant. Both phytase sources are derived from an Escherichia coli (E. coli) gene; however, OP is expressed in Pichia pastoris whereas QB is expressed in Trichoderma reesei (Gonçalves et al., 2016; Dersjant-Li et al., 2015). Manufacturers of phytase often recommend doses of 1,000 to 1,500 FTU/kg for broiler chickens (ABVista, Woodstock Ct, Marlborough; Huvepharma, Sofia, Bulgaria)

The objective of this study was to compare live weight gain (LWG), feed intake (FI), mortality corrected feed conversion ratio (FCR), boneless, skinless breast yield, $\mathrm{P}$ and $\mathrm{Ca}$ mineral digestibility, and tibia ash responses of Ross 708 broilers to increasing doses of two phytase sources at 500, 1,000, or 2,000 FTU/kg.

\section{MATERIALS AND METHODS}

\section{Diet Formulation and Batching}

Corn and soybean meal-based diets were formulated using the 2019 Ross broiler nutrition specifications (Table 1). A nutritionally adequate positive control (PC) diet and a negative control (NC) diet with reduced non-phytate phosphorus (nPP) $(0.2 \%)$ and Ca $(0.2 \%)$ were formulated. The phytase sources were added separately to different allotments of the NC diet and each mixed with the remaining NC diet to achieve different concentrations. 
Phytase concentrations for each source was calculated based on the activity level declared on the product labels. The NC diet was batched and weighed, then split into two equal allotments. One of the allotments was split in half. Optiphos Plus was top dressed to one of the halves to achieve a 2,000 FTU/kg activity level. A mixture of equal portions of the 2,000 FTU/kg treatment and the NC treatment was performed to achieve the $1,000 \mathrm{FTU} / \mathrm{kg}$ treatment. A second mixture of equal portions of the 1,000 FTU/kg treatment and the NC treatment was performed to achieve the $500 \mathrm{FTU} / \mathrm{kg}$ treatment. The process was repeated for QB with the second NC allotment. A portion of the NC diet remained free from phytase. A total of eight treatments were manufactured per feeding phase (Table 1). Three phases were formulated, a starter (1-20 d), grower (21-35 d), and finisher (36-44 d), for a total of 24 diets. Titanium dioxide $\left(\mathbf{T i O}_{2}\right)$ was included as an indigestible marker at a $0.2 \%$ inclusion rate to the finisher diet for $\mathrm{P}$ and $\mathrm{Ca}$ mineral analysis.

\section{Feed Manufacture}

All feed was manufactured at the West Virginia University pilot feed mill located in Morgantown, West Virginia. A $454 \mathrm{~kg}$ high fiber ruminant diet was pelleted as a warmup for the mill equipment prior to pelleting each feeding phase. Each batch was given a 10 min dry mix time subsequent to enzyme addition, then mixed for an additional 10 min post soybean oil fat addition. Each phytase source was mixed with approximately $3 \mathrm{~kg}$ of the NC master batch in a Univex paddle mixer (Univex Floor Paddler Mixer, Model: M12B, Univex Corporation, Salem, NH) for five minutes prior to final mixing in a Weighronix one-ton single screw vertical mixer. Each diet was conditioned at $82^{\circ} \mathrm{C}$ for $30 \mathrm{sec}$ utilizing a California Pellet Mill (CPM) conditioner, CPM hygieniser, 40 HP pellet mill (Master Model Pellet Mill, CPM, Crawfordsville, IN), and 4.8 x 38mm CPM pellet die was utilized. The feeder rate from the surge bin to the conditioner remained constant at $32 \%$ for all treatments and phases. Production rate remained constant for all treatments and phases. Ten, 500-gram 
mash samples per treatment were collected from the surge bin and composited and thoroughly mixed for each treatment and feeding phase to ensure a representative sample. Ten, 500-gram pelleted samples were collected after achieving a steady state conditioning temperature of $82^{\circ} \mathrm{C}$. Pellets were collected immediately after pellet die extrusion and cooled for 12 minutes on cheesecloth covering a large agricultural fan, similar to the methodologies of Reese et al. (2017) with the goal of limiting potential nutrient segregation effects of sampling post-pellet auguring. Samples were then composited and mixed for each treatment and feeding phase. Composite pellet samples of each treatment per phase were sent to a commercial laboratory for $\mathrm{Ca}, \mathrm{nPP}$, crude protein $(\mathbf{C P})$, and phytic acid ion exchange analysis (NP Analytical Laboratories). Pelleted sample of the finisher diet was also sent to a commercial laboratory for $\mathrm{TiO}_{2}$ and mineral analysis (ATC Scientific, Little Rock). Mash and pelleted samples were sent to a commercial laboratory for phytase analysis (Eurofins Food and Feed Testing, Des Moines, IA). Phytase levels were analyzed using the ISO 30024 method on an average of four samples per diet for the starter and finisher phases and two samples per diet for the grower.

\section{Particle Size and Pellet Durability Analysis}

Particle size was determined for each crumbled diet from the starter diets one using a WS Tyler Ro-Tap RX-29 Sieve Shaker where 100 gram of complete crumble samples were subjected to force through multiple sized enclosed screens for 10 minutes (Table 2). Pellet durability index (PDI) was determined on starter, grower, and finisher diets using a New

Holman Pellet Tester (U.S.A Standard Test Sieve. No. 6. W.S. Tyler. Mentor, OH). Pelleted samples from each treatment were individually sifted through a NO. 5 W. S. Tyler testing sieve to remove fines. One hundred grams of sifted pellets were placed in the New Holman Tester perforated chamber, where they were subjected to forced air for 30 seconds. 
Remaining pellets were weighed and recorded as a percentage. Descriptive data of mill specs are presented in Table 2.

\section{Bird Performance}

A group of 1,920 Hubbard $\times$ Ross 708-day-old male chicks were obtained from a local hatchery (Longnecker's Hatchery, Elizabeth Town, PA). Treatments were fed utilizing a randomized complete block design. On d1 birds were weighed in groups of 30 and allocated to 64 floor pens based on weight to create uniform initial pen weights. Groups were randomly assigned to each block. The lighting schedule was as follows: 24L:0D from d0 to d3, 23L:1D from d4 to d7, 20L:4D from d8 to d24, and 18L:6D from d25 to d44 (Boney and Moritz, 2017). Feed and water were provided for ad libitum consumption via hoppers and nipple drinkers respectively. Two identical rooms were utilized, cross ventilated and heated with forced air heating. Performance parameters were recorded on d20, d35, and d44. Performance parameters included FI per bird, bird weight (BW), LWG per bird, and FCR.

On day 44 each bird was weighed individually and two birds per pen most closely representing the average pen weight were selected for boneless, skinless breast extraction to determine total breast weight and hot boneless, skinless breast as a percent of hot carcass weight. Birds were exsanguinated and immediately processed. Feet, head, neck, and viscera were removed. The carcass weight was recorded, then the skin on the breast was removed and discarded. Both sides of the breast were excised from the keel bone and weighed as a unit. Boneless, skinless breast weight to carcass weight was calculated and the mean percent between the two birds per pen was used for statistical analysis. Breast removal was performed by the same two people throughout the entirety of the process, where each person processed one bird per pen for uniformity. All animals were reared according to protocols approved by West Virginia University Animal Care and Use Committee. 


\section{Bone Mineralization}

On d20, four birds per pen were randomly selected and euthanized via cervical dislocation. On d44, four birds per pen with a weight nearest to the mean pen weight were selected and euthanized via cervical dislocation. For both time periods, the left tibia was excised from each bird, and tibiae from each pen were pooled to determine dry-defatted tibia ash percent and mg ash per chick. The sample group of tibia excised birds on d20 was included in d35 mortality for mortality corrected bird performance calculations. The tibiae were placed in a freezer until the bone mineralization process began.

The tibiae were removed from the freezer and placed in a drying oven set at $105^{\circ} \mathrm{C}$ for 48 hours, upon which they were wrapped in filter paper and allocated into a Soxhlet apparatus for fat extraction via flushing with petroleum ether for 16 hours. Once removed from the Soxhlet, they were left to sit in the laboratory hood overnight, then filter paper was removed, and they were weighed by pen and placed in an ashing oven set at $600^{\circ} \mathrm{C}$ for 18 hours. The remaining material was weighed for tibia ash determination and mg ash per chick calculations (Boney and Moritz, 2017).

\section{Mineral Digestibility}

On $\mathrm{d} 44$, the same four birds that were utilized for tibia excision were selected to determine apparent ileal Ca digestibility (AID Ca) and apparent ileal P digestibility (AID P). The ileum from Meckel's diverticulum to the ileo-cecal-colonic junction was excised from each bird, similar to the procedure outlined by Lamp et al. (2020). This section was cut in half, and the lower portion nearest the ileo-cecal-colonic junction was gently flushed with distilled water into clean plastic cups. The ileal contents were pooled per pen. The contents of each cup were frozen, then freeze dried at $-40^{\circ} \mathrm{C}$. Samples were sent to a commercial laboratory for $\mathrm{TiO}_{2}, \mathrm{Ca}$, and $\mathrm{P}$ analysis (ATC Scientific, Little Rock). 
Apparent ileal nutrient ( $\mathrm{Ca}$ and $\mathrm{P})$ digestibility coefficients were calculated according to Adedokun and coauthors (2015).

AID Ca/AID P coefficient $(\%)=\left[1-\left(\right.\right.$ TiO $_{2 \text { Diet }} /$ TiO 2 2igesta $) x($ Nutrient Digesta Nutrient Diet) $] * 100$

The digestible $\mathrm{Ca}$ and $\mathrm{P}$ concentrations of the diet were calculated using the following equation:

Digestible $\mathrm{P} /$ digestible $\mathrm{Ca}$ concentration $(\%)=$ (AID nutrien(\%)/100) $x$ Nutrient Diet $(\%)$

Where $\mathrm{TiO}_{2}$ Digesta and $\mathrm{TiO}_{2}$ Diet are the analyzed concentrations of $\mathrm{TiO}_{2}(\%)$ in the digesta and diets, respectively, and Nutrient Digesta and Nutrient Diet are the analyzed concentrations of Ca or $\mathrm{P}$ in the digesta and diets, respectively.

\section{STATISTICAL ANALYSIS}

Multiple comparisons between mean values of the eight treatments were conducted using ANOVA within SAS 9.4 (SAS Institute, 2017). Interactions between phytase sources and level were also evaluated using Fisher's LSD test when the main effect interaction was significant. The pen served as the experimental unit for all parameters. A 3 (Phytase level) $\times$ 2 (Phytase source) factorial arrangement within a randomized complete block design was utilized. Blocks were determined by the location of pens in each room. Alpha was designated as 0.05 for significance and 0.10 for trending data, and letter superscripts were used to denote differences among treatment means.

\section{RESULTS AND DISSCUSSION}

The results of this experiment are presented in Tables 3-5. Descriptive feed manufacture data can be found in Table 2. Crumble particle size for the starter phase was similar among treatments. Measured values for PDI were also similar among treatments 
within each feeding phase. Analyzed phytase activity of mash and pelleted diets can be found in Table 1. The average recovery rate of QB was $86.81 \%$, while OP averaged a $94.73 \%$ recovery rate.

Day 20 bird performance data showed expected NC and PC differences as well as main effects for phytase source for bird weight $(P=0.0420)$ and LWG $(P=0.0485)$. Birds supplemented with OP had a significant increase in bird weight (12g) and LWG (13g) compared to birds receiving QB. Similar to the results of Leyva-Jimenez and coauthors (2019), FCR of birds fed diets containing either phytase source at any level were similar to those fed the PC diet, while birds fed the NC diet were impaired. No significant difference was observed in FI or percent mortality between the eight treatments.

Differences between the PC and NC treatments were as expected for d20 tibia ash percent and mg tibia ash (Table 5). A main effect for phytase level was observed for d20 tibia ash percent $(P=0.002)$. Tibiae from birds fed diets containing either 1,000 or $2,000 \mathrm{FTU} / \mathrm{kg}$ of either source had the greatest percent tibia ash. Higher mg tibia ash was produced by OP at $500 \mathrm{FTU} / \mathrm{kg}$ relative to QB at $500 \mathrm{FTU} / \mathrm{kg}(P<0.05)$. Past literature has documented an increase in the mineral deposition of broiler chickens with the inclusion of greater concentrations of phytase in the diet (Fernandes et al., 2019; Shirley and Edwards, 2003). It is suggested from the results that the $\mathrm{P}$ liberation from phytate is greater when higher concentrations of phytase are fed, leading to greater bone mineralization regardless of the source of phytase.

No main effect differences were observed for $\mathrm{d} 35$, and the differences between the PC and $\mathrm{NC}$ treatments were as expected. Thus, data for $\mathrm{d} 35$ performance was omitted to maintain a more concise research report.

On d44, there were expected differences between the PC and NC treatments for BW and LWG (Table 4). A main effect for phytase level for FCR was observed on d44 
$(P=0.037)$. Birds provided $500 \mathrm{FTU} / \mathrm{kg}$ of either source had the lowest FCR, 1,000 FTU/kg had the highest, and 2,000 FTU/kg was intermediate. The authors do not have an explanation for these differences but speculate that there may be an association between phytase concentration and dietary substrate. However, it should be noted that the greatest difference among levels was only 3 points.

The increased weights observed in birds supplemented with OP compared to QB on d20 were no longer evident on d44. Walk and Rao (2020) had similar results and suggested that the age of the bird in part dictates the magnitude of response to phytase. It was suggested that younger birds require higher concentrations of phytase to optimize BWG when compared to older birds.

No significant differences were found between treatments for hot boneless, skinless breast measurements (Table 5). Past research has found an increase in broiler breast yield in response to phytase supplementation (Smith et al., 2019; Campasino et al., 2014). This may be due to phytate chelating with amino acids and proteins, rendering them unavailable for absorption. The addition of phytase may have released these amino acids from chelation, subsequently allowing for increasing breast yields.

Differences between the PC and NC treatments were as expected for $\mathrm{d} 44$ tibia ash percent and mg tibia ash (Table 5). Day 44 tibia ash percent was affected by the interaction of phytase level and source $(P=0.023)$. There was no significant difference between sources at $500 \mathrm{FTU} / \mathrm{kg}$; however, at levels greater than $500 \mathrm{FTU} / \mathrm{kg}$ OP had a higher tibia ash percent. A larger increase in mg tibia ash was observed for 2,000 FTU/kg OP compared to the same concentration of $\mathrm{QB}(P<0.05)$.

Differences between the PC and NC treatments for d44 AID P were as expected (Table 5). A main effect for phytase source was observed for AID Ca $(P=0.0005)$. AID Ca increased in broilers fed OP relative to QB. The increase in $\mathrm{d} 44$ percent tibia ash discussed 
previously may have been caused in part by this increase in Ca digestibility. A phytase level main effect occurred for AID P, where digestibility increased in a stepwise manner as the phytase level increased $(P=0.0096)$. These results are in agreement with the $\mathrm{d} 20$ bone mineralization results. More $\mathrm{P}$ was liberated from phytate and digested with greater concentrations of phytase, allowing for greater bone mineralization.

\section{CONCLUSIONS AND APPLICATIONS}

1. The average enzyme recovery rate was $87 \%$ and $95 \%$ for QB and OP, respectively.

2. Both phytase sources, $\mathrm{OP}$ and $\mathrm{QB}$, performed similarly in regard to $\mathrm{d} 44$ performance, breast tissue accretion, and AID P and both improved bird performance metrics compared to the $\mathrm{NC}$ treatment at all three inclusion levels.

3. OP resulted in $44 \mathrm{~d}$ birds with a significantly greater percentage tibia ash and AID Ca than birds supplemented with QB. Source differences may be associated with post pelleting phytase activity that differed between sources formulated to 1,000 and 2,000 FTU/kg.

\section{REFERNECES AND NOTES}

1. ABVista, Woodstock Ct, Marlborough.

2. ATC Scientific, Little Rock, Arkansas.

3. Boney, J. W., and J. S. Moritz. 2017. Phytase dose effects in practically formulated diets that vary in ingredient composition on feed manufacturing and broiler performance. J. Appl. Poult. Res. 26:273-285.

4. Boroojeni, F. G., B. Svihus, H. G. von Reichenbach, and J. Zentek. 2016. The effects of hydrothermal processing on feed hygiene, nutrient availability, intestinal microbiota and morphology in poultry-A review. Anim. Feed. Sci. Tech. 220:187-215.

5. Campasino, A., T. York, C. Wyatt, M. R. Bedford, and W. A. Dozier III. 2014. Effect of increasing supplemental phytase concentration in diets fed to Hubbardx Cobb 500 male broilers from 1 to 42 days of age. J. Appl. Poult. Res. 23:705-714.

6. De Bruyne, K. 2000. New strategies in supplementation of phosphorus discussed. Feedstuffs. 6:1-13.

7. Dersjant-Li, Y., A. Awati, H. Schulze, and G. Partridge. 2015. Phytase in nonruminant animal nutrition: a critical review on phytase activities in the gastrointestinal tract and influencing factors. J. Sci. Food. Agric. 95:878-896. 
8. Experiment Station Chemical Laboratories, Agricultural Experiment Station, University of Missouri, Columbia.

9. Fernandes, J. I. M., D. Horn, E. J. Ronconi, R. Buzim, F. K. Lima, and D. A. Pazdiora. 2019. Effects of phytase superdosing on digestibility and bone integrity of broilers. J. Appl. Poultry. Res. 28:390-398.

10. Gonçalves, M. A., S. S. Dritz, M. D. Tokach, J. M. DeRouchey, J. C. Woodworth, and R. D. Goodband. 2016. Fact sheets-comparing phytase sources for pigs and effects of superdosing phytase on growth performance of nursery and finishing pigs. J. Swine. Health. Prod. 24:97-101.

11. Huvepharma, Sofia, Bulgaria.

12. Jongbloed, A. W., and P. A. Kemme. 1990. Effect of pelleting mixed feeds on phytase activity and the apparent absorbability of phosphorus and calcium in pigs. Anim. Feed. Sci. Tech. 28:233-242.

13. Lamp, A. E., A. Mereu, I. Ruiz-Ascacibar, and J. S. Moritz. 2020. Inorganic feed phosphate type determines mineral digestibility, broiler performance, and bone mineralization. J. Appl. Poult. Res. 29:559-572.

14. Leyva-Jimenez, H., A. M. Alsadwi, K. Gardner, E. Voltura, and C. A. Bailey. 2019. Evaluation of high dietary phytase supplementation on performance, bone mineralization, and apparent ileal digestible energy of growing broilers. Poult. Sci. 98:811-819.

15. Longnecker's Hatchery, Elizabeth Town, PA.

16. Master Model Pellet Mill, California Pellet Mill Company, Crawfordsville, IN.

17. New Holmen Portable Pellet Durability Tester, Lignotech USA Inc., Rothschild, WI.

18. NP Analytical Laboratories, St. Louis, MO.

19. Reese, D. A., K. L. Foltz, and J. S. Moritz. 2017. Effect of mixing and sampling method on pelleted feed nutrient analysis and diet formulation validation. J. Appl. Poult. Res. 26:219-225.

20. Shirley, R. B., and H. M. Edwards Jr. 2003. Graded levels of phytase past industry standards improves broiler performance. Poult. Sci. 82:671-680.

21. Slominski, B. A., T. Davie, M. C. Nyachoti, and O. Jones. 2007. Heat stability of endogenous and microbial phytase during feed pelleting. Livest. Sci. 109:244-246.

22. Smith, K. A., C. L. Wyatt, and J. T. Lee. 2019. Evaluation of increasing levels of phytase in diets containing variable levels of amino acids on male broiler performance and processing yields. J. Appl. Poult. Res. 28:253-262.

23. Timmons, J. R., R. Angel, J. M. Harter-Dennis, W. W. Saylor, and N. E. Ward. 2008. Evaluation of heat-stable phytases in pelleted diets fed to broilers from day zero to thirty-five during the summer months. J. Appl. Poultry. Res. 17:482-489.

24. U.S.A Standard Test Sieve. No. 6. W.S. Tyler. Mentor, OH.

25. Univex Floor Paddler Mixer, Univex Corporation, Salem, NH.

26. Walk, C. L., and S. R. Rao. 2020. Dietary phytate has a greater anti-nutrient effect on feed conversion ratio compared to body weight gain and greater doses of phytase are required to alleviate this effect as evidenced by prediction equations on growth performance, bone ash and phytate degradation in broilers. Poult. Sci. 99:246-255.

27. Wyss, M., L. Pasamontes, R. Rémy, J. Kohler, E. Kusznir, M. Gadient, F. Müller, and A. P. van Loon. 1998. Comparison of the Thermostability Properties of Three Acid Phosphatases from Molds: Aspergillus fumigatusPhytase, A. niger Phytase, and A. nigerpH 2.5 Acid Phosphatase. Appl. Environ. Microb. 64:4446-4451. 
Table 1. Broiler diet formulations and analyzed values of pelleted diets ${ }^{1}$

\begin{tabular}{|c|c|c|c|c|c|c|c|c|}
\hline \multirow[b]{2}{*}{ Ingredients } & \multicolumn{2}{|c|}{ Starter } & \multicolumn{2}{|c|}{ Grower } & \multicolumn{2}{|c|}{ Finisher } & & \\
\hline & $\begin{array}{l}\text { Positive } \\
\text { Control }\end{array}$ & $\begin{array}{l}\text { Negative } \\
\text { Control }\end{array}$ & $\begin{array}{l}\text { Positive } \\
\text { Control }\end{array}$ & $\begin{array}{l}\text { Negative } \\
\text { Control }\end{array}$ & $\begin{array}{l}\text { Positive } \\
\text { Control }\end{array}$ & $\begin{array}{l}\text { Negative } \\
\text { Control }\end{array}$ & & \\
\hline Corn & 51.8 & 53.5 & 58.4 & 60.2 & 62.9 & 64.7 & & \\
\hline Soybean Meal (46\%) & 41.5 & 41.3 & 33.4 & 33.2 & 30.2 & 29.9 & & \\
\hline Soy Oil & 2.63 & 2.06 & 4.51 & 3.95 & 3.74 & 3.17 & & \\
\hline Dicalcium Phosphate & 1.96 & 0.88 & 1.86 & 0.78 & 1.10 & 0.00 & & \\
\hline Limestone & 0.81 & 0.94 & 0.76 & 0.89 & 0.83 & 0.97 & & \\
\hline Salt & 0.33 & 0.33 & 0.33 & 0.33 & 0.33 & 0.32 & & \\
\hline DL - Methionine & 0.32 & 0.32 & 0.24 & 0.24 & 0.22 & 0.21 & & \\
\hline Vitamin/Mineral Premix ${ }^{2}$ & 0.25 & 0.25 & 0.25 & 0.25 & 0.25 & 0.25 & & \\
\hline Lysine - $\mathrm{HCl}$ & 0.12 & 0.12 & 0.04 & 0.04 & 0.05 & 0.06 & & \\
\hline Threonine & 0.09 & 0.09 & 0.02 & 0.02 & 0.02 & 0.02 & & \\
\hline Sodium Bicarbonate & 0.10 & 0.10 & 0.10 & 0.10 & 0.10 & 0.10 & & \\
\hline Choline 60 & 0.13 & 0.13 & 0.11 & 0.11 & 0.10 & 0.10 & & \\
\hline Titanium Dioxide ${ }^{3}$ & - & - & - & - & 0.20 & 0.20 & & \\
\hline Phytase (FTU/kg) ${ }^{4}$ & - & Top dress & - & Top dress & - & Top dress & & \\
\hline \multicolumn{9}{|l|}{ Calculated Nutrient Values (\%) } \\
\hline $\mathrm{ME}(\mathrm{kcal} / \mathrm{lbs})$ & 3001 & 3001 & 3199 & 3199 & 3199 & 3199 & & \\
\hline Crude Protein & 23.0 & 23.0 & 19.5 & 19.5 & 18.3 & 18.3 & & \\
\hline Dig Lysine & 1.28 & 1.28 & 1.02 & 1.00 & 0.96 & 0.96 & & \\
\hline Dig Threonine & 0.86 & 0.86 & 0.68 & 0.68 & 0.64 & 0.64 & & \\
\hline Dig Methionine & 0.64 & 0.64 & 0.53 & 0.52 & 0.49 & 0.49 & & \\
\hline Dig TSAA & 0.95 & 0.95 & 0.80 & 0.80 & 0.75 & 0.75 & & \\
\hline Dig Tryptophan & 0.26 & 0.26 & 0.22 & 0.22 & 0.20 & 0.20 & & \\
\hline Calcium & 0.86 & 0.66 & 0.80 & 0.60 & 0.64 & 0.44 & & \\
\hline Non-phytate Phosphorus & 0.43 & 0.23 & 0.40 & 0.20 & 0.32 & 0.12 & & \\
\hline \multirow[t]{3}{*}{ Sodium } & 0.17 & 0.17 & 0.17 & 0.17 & 0.17 & 0.17 & & \\
\hline & \multicolumn{6}{|c|}{ Analyzed nutrient values $(\%)$} & & \\
\hline & $\mathrm{PC}$ & NC & $\begin{array}{c}\mathrm{NC}+500 \\
\text { FTU } / \mathrm{kg} \text { OP }\end{array}$ & $\begin{array}{l}\mathrm{NC}+1,000 \\
\text { FTU/kg OP }\end{array}$ & $\begin{array}{l}\mathrm{NC}+2,000 \\
\mathrm{FTU} / \mathrm{kg} \text { OP }\end{array}$ & $\begin{array}{c}\mathrm{NC}+500 \\
\text { FTU } / \mathrm{kg} \text { QB }\end{array}$ & $\begin{array}{l}\mathrm{NC}+1,000 \\
\text { FTU/kg QB }\end{array}$ & $\begin{array}{l}\mathrm{NC}+2,000 \\
\text { FTU/kg QB }\end{array}$ \\
\hline Crude Protein ${ }^{5}$ & 24.3 & 23.8 & 24.7 & 23.9 & 22.7 & 24.6 & 23.8 & 23.2 \\
\hline Calcium $^{6}$ & 1.02 & 0.96 & 0.85 & 0.74 & 0.79 & 0.77 & 0.84 & 0.76 \\
\hline Total Phosphorus $^{7}$ & 0.71 & 0.58 & 0.59 & 0.54 & 0.55 & 0.58 & 0.57 & 0.58 \\
\hline Phytic Acid Ion Exchange & 0.90 & 0.88 & 0.93 & 0.85 & 0.77 & 0.90 & 0.87 & 0.88 \\
\hline Non-phytate Phosphorus ${ }^{8}$ & 0.46 & 0.33 & 0.32 & 0.30 & 0.33 & 0.33 & 0.32 & 0.34 \\
\hline Phytase (FTU/kg) Mash ${ }^{10}$ & - & - & 586.3 & 848.8 & 2062.5 & 463.5 & 651.3 & 1028.5 \\
\hline Phytase (FTU/kg) Pellets ${ }^{10}$ & 51.3 & 52.5 & 466.3 & 762.0 & 2062.5 & 417.5 & 643.8 & 864.0 \\
\hline Crude Protein & 20.4 & 20.4 & 20.2 & 20.6 & 20.7 & 20.9 & 20.7 & 20.0 \\
\hline Calcium & 0.67 & 0.58 & 0.61 & 0.61 & 0.65 & 0.59 & 0.63 & 0.64 \\
\hline Total Phosphorus & 0.61 & 0.48 & 0.45 & 0.48 & 0.46 & 0.47 & 0.48 & 0.49 \\
\hline Phytic Acid Ion Exchange & 0.83 & 0.84 & 0.59 & 0.44 & 0.28 & 0.71 & 0.47 & 0.17 \\
\hline Non-phytate Phosphorus & 0.38 & 0.24 & 0.28 & 0.35 & 0.38 & 0.27 & 0.34 & 0.45 \\
\hline Phytase (FTU/kg) Mash & 85.0 & 65.0 & 500.0 & 1005.0 & 1830.0 & 455.0 & 732.5 & 1247.5 \\
\hline Phytase (FTU/kg) Pellets & 50.0 & 52.5 & 447.5 & 1047.5 & 2115.0 & 372.5 & 667.5 & 773.8 \\
\hline Crude Protein & 19.3 & 19.6 & 19.5 & 19.7 & 19.3 & 19.9 & 20.1 & 20.1 \\
\hline Calcium & 0.70 & 0.49 & 0.53 & 0.54 & 0.51 & 0.53 & 0.62 & 0.50 \\
\hline Total Phosphorus & 0.51 & 0.34 & 0.33 & 0.32 & 0.33 & 0.34 & 0.35 & 0.32 \\
\hline Phytic Acid Ion Exchange & 0.72 & 0.83 & 0.60 & 0.54 & 0.46 & 0.75 & 0.62 & 0.41 \\
\hline Non-phytate Phosphorus & 0.31 & 0.11 & 0.16 & 0.17 & 0.20 & 0.13 & 0.18 & 0.20 \\
\hline Phytase (FTU/kg) Mash & 50.0 & 50.0 & 520.0 & 951.3 & 1805.0 & 592.5 & 902.5 & 1376.0 \\
\hline Phytase (FTU/kg) Pellets & 0.00 & 0.00 & 499.0 & 928.0 & 1699.0 & 555.0 & 762.0 & 1064.0 \\
\hline
\end{tabular}

$\mathrm{OP}=$ Optiphos Plus, $\mathrm{QB}=$ Quantum Blue.

'Nutrient requirements are based on 2019 Ross Broiler Nutrition Specifications for target

live wight of $2.5-3.00 \mathrm{~kg}, 0-10 \mathrm{~d}$

'Supplied the following per kilogram of diet: manganese, $0.02 \%$; $0.02 \%$; zinc; iron, $0.01 \%$; copper, $0.0025 \%$; iodine, $0.0003 \%$; selenium, $0.00003 \%$; folic acid, $0.69 \mathrm{mg}$; choline, $386 \mathrm{mg}$;

riboflavin, $6.61 \mathrm{mg}$; biotin, $0.03 \mathrm{mg}$; vitamin $\mathrm{B} 6,1.38 \mathrm{mg}$; niacin, $27.56 \mathrm{mg}$; pantothenic acid, $6.61 \mathrm{mg}$; thiamine, $2.20 \mathrm{mg}$; menadione, $0.83 \mathrm{mg}$; vitamin B12, $0.01 \mathrm{mg}$; vitamin E,

16.53 IU; vitamin D3, 2,133 ICU; vitamin A, 7,716 IU.

${ }^{3}$ Titanium Dioxide was utilized as an indigestible marker.

${ }^{4}$ Phytase (optiphos plus or quantum blue) was top dressed at 2,000 FTU/kg and calculated amounts were blended with the negative control treatment to achieve the desired concentrations of $1,000 \mathrm{FTU} / \mathrm{kg}$ and $500 \mathrm{FTU} / \mathrm{kg}$.

AOAC Method 988.05, 920.87, 991.20; Kjeldahl.

${ }^{6}$ AOAC Method 968.08, 927.02, 935.13, 985.35; Atomic Absorption Spectrophotometry.

${ }^{7} \mathrm{AOAC}$ Method 965.17; Spectrophotometry.

${ }^{8} \mathrm{AOAC}$ Method 986.11.
${ }^{9}$ Non-phytate phosphorus $=$ total phosphorus $($ AOAC Method 965.17) $-[0.282 \times$ phytic acid $] \times 100$.

${ }^{1} \mathrm{AOAC}$ method 2000.12. 


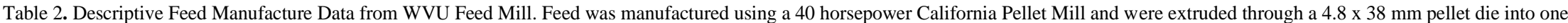
positive control batch and seven negative control batches for each feeding phase.

\begin{tabular}{|c|c|c|c|c|c|c|c|c|c|c|c|c|}
\hline $\begin{array}{l}\text { Feeding } \\
\text { Phase }\end{array}$ & Treatment & $\begin{array}{c}\text { Ambient } \\
\text { Temperature } \\
\left({ }^{\circ} \mathrm{C}\right)\end{array}$ & $\begin{array}{c}\text { Ambient } \\
\text { Humidity } \\
(\%)\end{array}$ & $\begin{array}{c}\text { Mash } \\
\text { Temperature } \\
\left({ }^{\circ} \mathrm{C}\right)\end{array}$ & $\begin{array}{l}\text { Conditioning } \\
\text { Temperature } \\
\left({ }^{\circ} \mathrm{C}\right)\end{array}$ & $\begin{array}{c}\text { Conditioning } \\
\text { Time }\end{array}$ & $\begin{array}{l}\text { Mill } \\
\text { Load }^{2} \\
(\%)\end{array}$ & $\begin{array}{c}\text { Hygienizer } \\
\text { Temperature } \\
\left({ }^{\circ} \mathrm{C}\right)\end{array}$ & $\begin{array}{c}\text { Hot Pellet } \\
\text { Temperature } \\
\left({ }^{\circ} \mathrm{C}\right)\end{array}$ & $\begin{array}{c}\text { New } \\
\text { Holmen } \\
\text { Pellet } \\
\text { Durability } \\
\text { Tester }^{5} \\
(\%) \\
\end{array}$ & $\begin{array}{l}\text { Crumble } \\
\text { Particle } \\
\text { Size }^{6} \\
(\mu \mathrm{m})\end{array}$ & $\begin{array}{l}\text { Pellets } \\
\text { to Fines }{ }^{7} \\
\quad(\%)\end{array}$ \\
\hline \multirow{8}{*}{$\begin{array}{c}\text { Starter } \\
\text { (Day 0- } \\
20)\end{array}$} & $\mathrm{PC}$ & 27 & 38 & 32 & 82 & 30 & 40.0 & 75 & 82.8 & 67 & 1156 & - \\
\hline & $\mathrm{NC}$ & 27 & 42 & 31 & 82 & 30 & 40.0 & 73 & 82.9 & 58 & 1326 & - \\
\hline & $\mathrm{NC}+500 \mathrm{OP}$ & 28 & 39 & 35 & 82 & 30 & 40.0 & 76 & 83.2 & 57 & 1253 & - \\
\hline & $\mathrm{NC}+1000 \mathrm{OP}$ & 28 & 39 & 33 & 82 & 30 & 40.0 & 75 & 82.3 & 62 & 1308 & - \\
\hline & $\mathrm{NC}+2000 \mathrm{OP}$ & 27 & 38 & 33 & 82 & 30 & 40.0 & 75 & 82.6 & 56 & 1264 & - \\
\hline & $\mathrm{NC}+500 \mathrm{QB}$ & 27 & 42 & 32 & 82 & 30 & 40.0 & 74 & 82.7 & 57 & 1313 & - \\
\hline & $\mathrm{NC}+1000 \mathrm{QB}$ & 27 & 41 & 33 & 82 & 30 & 40.0 & 75 & 82.6 & 58 & 1347 & - \\
\hline & $\mathrm{NC}+2000 \mathrm{QB}$ & 28 & 38 & 33 & 82 & 30 & 40.0 & 75 & 82.8 & 59 & 1245 & - \\
\hline \multirow{8}{*}{$\begin{array}{c}\text { Grower } \\
\text { (Day 21- } \\
35)\end{array}$} & $\mathrm{PC}$ & 13 & 55 & 28 & 82 & 30 & 38.0 & 74 & 80.6 & 36 & - & 39 \\
\hline & $\mathrm{NC}$ & 12 & 84 & 26 & 82 & 30 & 38.5 & 75 & 80.3 & 45 & - & 52 \\
\hline & $\mathrm{NC}+500 \mathrm{OP}$ & 16 & 52 & 22 & 82 & 30 & 38.0 & 71 & 81.4 & 35 & - & 62 \\
\hline & $\mathrm{NC}+1000 \mathrm{OP}$ & 18 & 46 & 24 & 82 & 30 & 38.0 & 71 & 81.4 & 32 & - & 68 \\
\hline & $\mathrm{NC}+2000 \mathrm{OP}$ & 20 & 41 & 22 & 82 & 30 & 37.5 & 69 & 80.9 & 38 & - & 63 \\
\hline & $\mathrm{NC}+500 \mathrm{QB}$ & 13 & 78 & 23 & 82 & 30 & 38.0 & 75 & 81.6 & 44 & - & 54 \\
\hline & $\mathrm{NC}+1000 \mathrm{QB}$ & 14 & 68 & 23 & 82 & 30 & 38.0 & 73 & 81.7 & 41 & - & 62 \\
\hline & $\mathrm{NC}+2000 \mathrm{QB}$ & 14 & 59 & 22 & 82 & 30 & 38.0 & 72 & 80.8 & 39 & - & 60 \\
\hline \multirow{8}{*}{$\begin{array}{l}\text { Finisher } \\
\text { (Day 36- } \\
44)\end{array}$} & $\mathrm{PC}$ & 21 & 33 & 21 & 82 & 30 & 39.0 & 72 & 82.3 & 75 & - & 57 \\
\hline & $\mathrm{NC}$ & 17 & 30 & 19 & 82 & 30 & 38.0 & 74 & 80.4 & 53 & - & 69 \\
\hline & $\mathrm{NC}+500 \mathrm{OP}$ & 19 & 26 & 20 & 82 & 30 & 37.0 & 73 & 81.4 & 40 & - & 32 \\
\hline & $\mathrm{NC}+1000 \mathrm{OP}$ & 20 & 26 & 21 & 82 & 30 & 37.5 & 72 & 81.4 & 42 & - & 46 \\
\hline & $\mathrm{NC}+2000 \mathrm{OP}$ & 21 & 25 & 20 & 82 & 30 & 37.5 & 73 & 81.3 & 43 & - & 45 \\
\hline & $\mathrm{NC}+500 \mathrm{QB}$ & 14 & 55 & 20 & 82 & 30 & 38.0 & 74 & 80.7 & 48 & - & 59 \\
\hline & $\mathrm{NC}+1000 \mathrm{QB}$ & 18 & 43 & 20 & 82 & 30 & 37.0 & 74 & 82.0 & 43 & - & 56 \\
\hline & $\mathrm{NC}+2000 \mathrm{QB}$ & 19 & 38 & 21 & 82 & 30 & 37.0 & 74 & 81.3 & 44 & - & 45 \\
\hline
\end{tabular}

$\mathrm{OP}=$ Optiphos Plus, $\mathrm{QB}=$ Quantum Blue.

${ }^{1}$ Conditioning temperature was measured as the reading from the conditioner temperature probe at the time of sample collection. This temperature was taken during a steady state position.

${ }^{2} \mathrm{~A} 100 \%$ motor load was based on FLA (full load amps) that was 47 amps based on the pellet mill motor name plate.

${ }^{3}$ The hygienizer was not turned on during this experiment; however, feed must run through the hygienzer for 45 seconds post conditioning and prior to pellet die extrusion based on the WVU feed manufacture system.

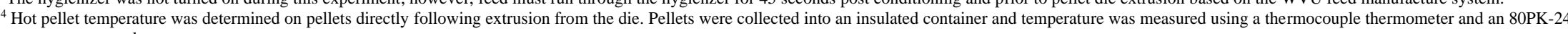
temperature probe.

${ }^{5}$ Durability was measured using the New Holmen Pellet Tester where 100 gram of pelleted samples are subjected to air flow within a perforated chamber for 30 seconds.

${ }^{6}$ Particle size was measured using the WS Tyler Ro-Tap RX-29 Sieve Shaker where 100 gram of complete crumble samples are subjected to force through multiple sized enclosed screens for 10 minutes.

${ }^{7}$ Pellets to fines as a percent of pellets remaining after sifting smaller particles through a \#5 screen to total volume of initial feed

*Diets were manufactured with steam reduced to 40 psig prior to Masoneilan valve. 
Table 3: D 0-20 Performance of Ross 708 broilers fed control feed and increasing doses of Optiphos Plus and Quantum Blue.

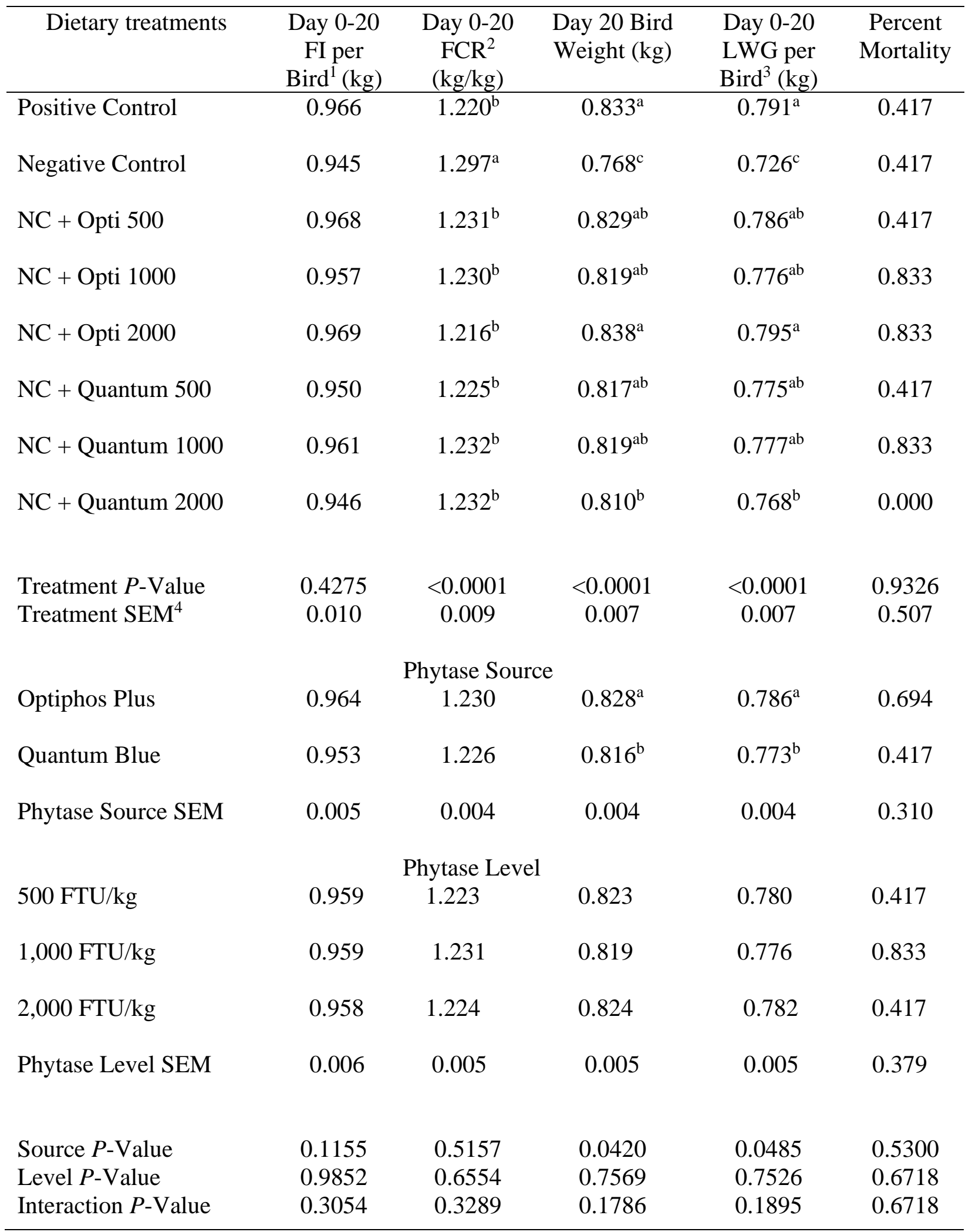

${ }^{3}$ Live Weight Gain

${ }^{4}$ Standard Error of the Mean

${ }^{\mathrm{a}-\mathrm{c}}$ Means within a column not sharing a common superscript differ significantly $(\mathrm{P}<0.05)$ 
Table 4: D 0-44 Performance of Ross 708 broilers fed control feed and increasing doses of Optiphos Plus and Quantum Blue.

\begin{tabular}{|c|c|c|c|c|c|c|}
\hline Dietary treatments & $\begin{array}{c}\text { Day 0-44 FI } \\
\text { per Bird }^{1} \\
(\mathrm{~kg})\end{array}$ & $\begin{array}{c}\text { Day 0-44 } \\
\text { FCR }^{2} \\
(\mathrm{~kg} / \mathrm{kg})\end{array}$ & $\begin{array}{c}\text { Day } 44 \\
\text { Bird weight } \\
(\mathrm{kg})\end{array}$ & $\begin{array}{l}\text { Day 0-44 } \\
\text { LWG per } \\
\operatorname{Bird}^{3}(\mathrm{~kg})\end{array}$ & $\begin{array}{l}\text { Percent } \\
\text { Mortality }\end{array}$ & $\begin{array}{c}\text { Day } 44 \\
\text { Standard } \\
\text { Deviation }^{4}\end{array}$ \\
\hline Positive Control & $5.392^{\mathrm{ab}}$ & $1.577^{\mathrm{ab}}$ & $3.301^{\mathrm{a}}$ & $3.252^{\mathrm{a}}$ & 15.152 & 0.285 \\
\hline Negative Control & $5.245^{\mathrm{b}}$ & $1.603^{\mathrm{a}}$ & $3.186^{\mathrm{b}}$ & $3.137^{\mathrm{b}}$ & 14.530 & 0.273 \\
\hline $\mathrm{NC}+$ Opti 500 & $5.382^{\mathrm{ab}}$ & $1.562^{\mathrm{b}}$ & $3.326^{\mathrm{a}}$ & $3.274^{\mathrm{a}}$ & 16.414 & 0.254 \\
\hline $\mathrm{NC}+$ Opti 1000 & $5.462^{\mathrm{a}}$ & $1.601^{\mathrm{a}}$ & $3.286^{\mathrm{a}}$ & $3.235^{\mathrm{a}}$ & 15.833 & 0.250 \\
\hline $\mathrm{NC}+$ Opti 2000 & $5.387^{\mathrm{ab}}$ & $1.568^{\mathrm{b}}$ & $3.319^{\mathrm{a}}$ & $3.269^{\mathrm{a}}$ & 15.417 & 0.269 \\
\hline NC + Quantum 500 & $5.336^{\mathrm{ab}}$ & $1.568^{\mathrm{b}}$ & $3.306^{\mathrm{a}}$ & $3.256^{\mathrm{a}}$ & 14.583 & 0.239 \\
\hline $\mathrm{NC}+$ Quantum 1000 & $5.430^{\mathrm{a}}$ & $1.578^{\mathrm{ab}}$ & $3.319^{\mathrm{a}}$ & $3.269^{\mathrm{a}}$ & 15.833 & 0.252 \\
\hline NC + Quantum 2000 & $5.339^{\mathrm{ab}}$ & $1.571^{\mathrm{b}}$ & $3.288^{\mathrm{a}}$ & $3.238^{\mathrm{a}}$ & 15.072 & 0.238 \\
\hline Treatment $P$-Value & 0.1730 & 0.0309 & 0.0190 & 0.0201 & 0.8751 & 0.6078 \\
\hline Treatment SEM $^{5}$ & 0.0532 & 0.0097 & 0.0273 & 0.0272 & 0.9890 & 0.0188 \\
\hline \multicolumn{7}{|c|}{ Phytase Source } \\
\hline Optiphos Plus & 5.410 & 1.577 & 3.310 & 3.260 & 15.888 & 0.258 \\
\hline Quantum Blue & 5.369 & 1.572 & 3.305 & 3.255 & 15.163 & 0.243 \\
\hline Phytase Source SEM & 0.030 & 0.006 & 0.016 & 0.016 & 0.562 & 0.010 \\
\hline \multicolumn{7}{|c|}{ Phytase Level } \\
\hline $500 \mathrm{FTU} / \mathrm{kg}$ & 5.359 & $1.565^{\mathrm{b}}$ & 3.316 & 3.265 & 15.499 & 0.247 \\
\hline 1,000 FTU/kg & 5.446 & $1.589^{\mathrm{a}}$ & 3.302 & 3.252 & 15.833 & 0.251 \\
\hline 2,000 FTU/kg & 5.363 & $1.570^{\mathrm{ab}}$ & 3.304 & 3.254 & 15.244 & 0.254 \\
\hline Phytase Level SEM & 0.037 & 0.007 & 0.019 & 0.019 & 0.688 & 0.013 \\
\hline Source $P$-Value & 0.328 & 0.548 & 0.807 & 0.827 & 0.368 & 0.321 \\
\hline Level $P$-Value & 0.177 & 0.037 & 0.864 & 0.866 & 0.833 & 0.929 \\
\hline Interaction $P$-Value & 0.986 & 0.290 & 0.459 & 0.465 & 0.611 & 0.665 \\
\hline
\end{tabular}


Table 5: Mineral Digestibility, Tibia Ash Analysis, and Breast Measurements of Ross 708 broilers fed control feed and increasing doses of Optiphos Plus and Quantum Blue.

\begin{tabular}{|c|c|c|c|c|c|c|c|c|}
\hline Dietary treatments & Day 44 AID Ca & Day 44 AID P & $\begin{array}{c}\text { Day } 20 \text { Tibia } \\
\text { Ash }(\%)\end{array}$ & $\begin{array}{c}\text { Day } 20 \text { Tibia } \\
\text { Ash } \\
\text { (mg/chick) }\end{array}$ & $\begin{array}{c}\text { Day } 44 \text { Tibia } \\
\text { Ash }(\%)\end{array}$ & $\begin{array}{c}\text { Day } 44 \\
\text { Tibia Ash } \\
\text { (mg/chick) }\end{array}$ & $\begin{array}{c}\text { Day } 44 \\
\text { Hot } \\
\text { Boneless, } \\
\text { Skinless } \\
\text { Breast } \\
\text { Weight } \\
\text { (g) } \\
\end{array}$ & $\begin{array}{c}\text { Day } 44 \\
\text { Hot } \\
\text { Boneless, } \\
\text { Skinless } \\
\text { Breast }^{2} \\
(\%)\end{array}$ \\
\hline Positive Control & $58.8^{\mathrm{a}}$ & $69.9^{\mathrm{bc}}$ & $48.4^{\mathrm{a}}$ & $904.94^{\mathrm{a}}$ & $47.9^{\mathrm{c}}$ & $3741.56^{\mathrm{ab}}$ & 796.65 & 31.3 \\
\hline Negative Control & $55.2^{\mathrm{a}}$ & $41.2^{\mathrm{d}}$ & $47.3^{\mathrm{d}}$ & $720.50^{d}$ & $45.7^{\mathrm{d}}$ & $2912.28^{c}$ & 755.64 & 31.2 \\
\hline $\mathrm{NC}+$ Opti 500 & $59.4^{\mathrm{a}}$ & $75.2^{\mathrm{ab}}$ & $47.8^{\mathrm{bcd}}$ & $875.06^{\mathrm{ab}}$ & $48.0^{\mathrm{c}}$ & $3652.34^{\mathrm{ab}}$ & 757.63 & 29.9 \\
\hline $\mathrm{NC}+$ Opti 1000 & $54.4^{\mathrm{a}}$ & $75.3^{\mathrm{ab}}$ & $48.3^{\mathrm{ab}}$ & $820.44^{\mathrm{bc}}$ & $48.9^{\mathrm{a}}$ & $3698.25^{\mathrm{ab}}$ & 756.26 & 30.2 \\
\hline $\mathrm{NC}+$ Opti 2000 & $64.5^{\mathrm{a}}$ & $80.2^{\mathrm{a}}$ & $48.3^{\mathrm{ab}}$ & $857.75^{\mathrm{abc}}$ & $48.8^{\mathrm{ab}}$ & $3797.03^{\mathrm{a}}$ & 762.34 & 30.2 \\
\hline $\mathrm{NC}+$ Quantum 500 & $42.0^{\mathrm{b}}$ & $66.2^{\mathrm{c}}$ & $47.7^{\mathrm{cd}}$ & $805.84^{c}$ & $48.1^{\mathrm{c}}$ & $3579.50^{\mathrm{b}}$ & 770.23 & 30.4 \\
\hline $\mathrm{NC}+$ Quantum 1000 & $40.7^{b}$ & $75.5^{\mathrm{ab}}$ & $48.1^{\mathrm{abc}}$ & $832.03^{\mathrm{bc}}$ & $48.1^{\mathrm{bc}}$ & $3770.34^{\mathrm{a}}$ & 771.31 & 30.3 \\
\hline $\mathrm{NC}+$ Quantum 2000 & $52.9^{\mathrm{ab}}$ & $80.7^{\mathrm{a}}$ & $48.4^{\mathrm{a}}$ & $834.25^{\mathrm{bc}}$ & $48.1^{\mathrm{c}}$ & $3593.44^{\mathrm{b}}$ & 756.56 & 30.1 \\
\hline Treatment $P$-Value & 0.0032 & $<0.0001$ & 0.0006 & $<0.0001$ & $<0.0001$ & $<0.0001$ & 0.6600 & 0.5800 \\
\hline Treatment SEM $^{1}$ & 4.379 & 3.054 & 0.197 & 21.388 & 0.256 & 60.535 & 16.5 & 0.57 \\
\hline \multicolumn{9}{|c|}{ Phytase Source } \\
\hline Optiphos Plus & $59.4^{\mathrm{a}}$ & 76.9 & 48.1 & 851.08 & $48.6^{\mathrm{a}}$ & 3715.88 & 758.74 & 30.1 \\
\hline Quantum Blue & $45.2^{\mathrm{b}}$ & 74.1 & 48.1 & 824.04 & $48.1^{b}$ & 3647.76 & 766.03 & 30.3 \\
\hline Phytase Source SEM & 2.630 & 1.733 & 0.095 & 12.764 & 0.096 & 35.191 & 10.13 & 0.330 \\
\hline \multicolumn{9}{|c|}{ Phytase Level } \\
\hline $500 \mathrm{FTU} / \mathrm{kg}$ & $50.7^{\mathrm{ab}}$ & $70.7^{\mathrm{b}}$ & $47.7^{b}$ & 840.45 & $48.0^{\mathrm{b}}$ & 3615.92 & 763.93 & 30.1 \\
\hline $1,000 \mathrm{FTU} / \mathrm{kg}$ & $47.6^{\mathrm{b}}$ & $75.4^{\mathrm{ab}}$ & $48.2^{\mathrm{a}}$ & 826.23 & $48.5^{\mathrm{a}}$ & 3734.30 & 763.78 & 30.3 \\
\hline 2,000 FTU/kg & $58.7^{\mathrm{a}}$ & $80.5^{\mathrm{a}}$ & $48.4^{\mathrm{a}}$ & 846.00 & $48.5^{\mathrm{a}}$ & 3695.23 & 759.45 & 30.2 \\
\hline Phytase Level SEM & 3.221 & 2.123 & 0.117 & 15.633 & 0.117 & 43.1 & 12.4 & 0.4 \\
\hline Source $P$-Value & 0.0005 & 0.2692 & 0.613 & 0.143 & 0.001 & 0.180 & 0.614 & 0.708 \\
\hline Level $P$-Value & 0.0534 & 0.0096 & 0.002 & 0.657 & 0.007 & 0.156 & 0.959 & 0.955 \\
\hline Interaction $P$-Value & 0.807 & 0.2142 & 0.709 & 0.201 & 0.023 & 0.092 & 0.811 & 0.863 \\
\hline
\end{tabular}

AID Ca $=$ Apparent ileal calcium digestibility

AID $\mathrm{P}=$ Apparent ileal phosphorus digestibility

${ }^{1}$ Standard Error of the Mean

${ }^{2}$ Hot skinless, boneless breast weight as a percent of total hot carcass weight

${ }^{\mathrm{a}-\mathrm{d}}$ Means within a column not sharing a common superscript differ significantly $(\mathrm{P}<0.05)$ 


\section{Kristina M. Bowen}

Home Address:

Morgantown WV, 26508

Kmb00014@mix.wvu.edu

\section{Education:}

Master's Degree in Nutritional and Food Science

Expected graduation $12 / 2021$

West Virginia University, Morgantown, WV

Current G.P.A: 4.0.

Bachelor's Degree in Animal Science Biology

Graduated

12/2019

Michigan State University (MSU), East Lansing, MI

3.93 G.P.A. (Summa Cum Laude)

Associate degree in Liberal Arts

Graduated

05/2016

St. Clair Community College (SC4), Port Huron, MI

4.0 G.P.A. (Summa Cum Laude)

Achievements and Volunteer:

- Head of a food drive at SC4 (2015)

- Head of a blood drive at SC4 (2015)

- Led fundraiser team to raise awareness of bipolar disorder (2015)

- Volunteer at SC4 Red Carpet Affair (2015)

- Phi Theta Kapa officer (2015-2016)

- Volunteer at Blue Water Area Humane Society (2016)

- Susan Friedrich Memorial Scholarship reward (2016)

\section{Teaching Experience:}

- Teaching assistant for:

- A\&VS 275 (Companion Animal Science)

- A\&VS (Poultry Judging)

- ANPR 369 (Poultry Production Lab)

- ANPR 367 (Poultry Production) Gave lectures on the management of pullets and laying hens in an industry setting.

- Assisted teaching visiting third, fourth, and fifth grade students about poultry (Feb 2020)

- Assisted in making videos for virtual CDE FFA poultry judging event where almost 100 members attended (Oct 2020)

\section{Oral Presentations:}

- 2020 International Poultry Scientific Forum (Athens, GA)

- Mass Mortality Composting of Spent laying hen carcasses during winter temperatures in the Upper Midwest. 
- 2021 Graduate Student Research and Creative Scholarship Day, WVU

- The effect of a dacitic tuff breccia $\left(\right.$ Azomite $\left.^{\circledR}\right)$ in corn, soybean, and DDGS based diets that vary in inorganic phosphate source on pellet mill energy consumption, live bird performance and amino acid digestibility.

- 2021 Poultry Science Association

- The effect of a dacitic tuff breccia (Azomite ${ }^{\circledR}$ ) in corn, soybean, and DDGS based diets that vary in inorganic phosphate source on pellet mill energy consumption, live bird performance and amino acid digestibility.

- 2021 Poultry Science Association

- Performance and Tibia ash Response of Ross 708 Broilers to increasing concentrations of Optiphos Plus and Quantum Blue Post Pelleting.

\section{Author Publications:}

\section{Peer-Reviewed manuscripts}

Boltz, T. P., J. Ferrel, K. M. Bowen, K. L. Harding, V. E. Ayres, and J. S. Moritz. 2021. The effect of a dacitic tuff breccia (Azomite $囚$ ) in corn, soybean, and DDGS based diets that vary in inorganic phosphate source on pellet mill production rate and pellet quality. J. Appl. Poult. Res. 30:100147

\section{State Extension}

- Wyoming County Outreach

- Involved several visits to Wyoming County to assist economically disadvantaged individuals gain knowledge about raising backyard laying hens (Mar 2020)

- Assisted in backyard broiler chicken processing (Oct 2020)

- Set up and judged live birds, eggs, and carcasses for Moorfield High School 4-H

- Poultry judge for Alleghany County Fair (Jul 2021)

- Poultry judge for Garrett Count Fair (Aug 2021)

- Gave oral presentation to industry leaders during Anitox meeting (Sep 2021)

\section{Work Experience:}

Poultry Barn Manager, 01/2020 - Current

West Virginia University, Morgantown, WV

- Responsible for the daily care of approximately 500 laying hens and roosters

- Responsible for barn upkeep and general maintenance

- Trained students on proper poultry handling and care

Intern at Weaver Brothers Farm, 05/2019 - 08/2019

Versailles, $\mathrm{OH}$

- Responsible for the daily tasks associated with several conventional caged and cage free barns including cleaning, floor egg collection, mortality checks, and system checks

- Spent several weeks at the feed mill where I learned about ingredient deliveries, diet formulations, and how to use the electronic system

- Gained more knowledge concerning cage free systems and care of laying hens 
- Assisted with weighing hens, vaccinations, and blood draw

- Worked with industry consultants

Spent Hen Composting Research Project, 2019

Michigan State University, East Lansing, MI

- Collected on-site data with Dr. Z. Williams and Dr. D. Rozeboom

Dairy Research Project Assistant, 2017 - 2018

Michigan State University, East Lansing, MI

- Responsible for in lab work such as compositing and grinding samples for Dr. M. VandeHaar. On-site work included collecting samples

Intern at Herbruck's Poultry Ranch, 05/2018 - 08/2018

Saranac, MI

- Gained experience with pullet and laying hen management

- Placed chicks

- Learned how to draw blood

- Weighed hens

- Minor maintenance experience gained

Farm Laborer/Interim Assistant Manager at the MSU Sheep Teaching and Research Center, 2016 - 2018

Michigan State University, East Lansing, MI

- Treated and cared for about 300 ewes and lambs

- Vaccinated and dewormed ewes

- Trimmed hooves

- Responsible for night checks for lambs

- Operated equipment such as skid steers, tractors, and hi-low trailers

Tutor at Achievement Center, 2015 - 2016

St. Clair County Community College, Port Huron, MI

- Helped students understand homework and succeed in class

Waitress/Hostess at Teds Coney Island, 2013 - 2014

Port Huron, MI

- Waited on tables

- took orders over the phone and drive through window 